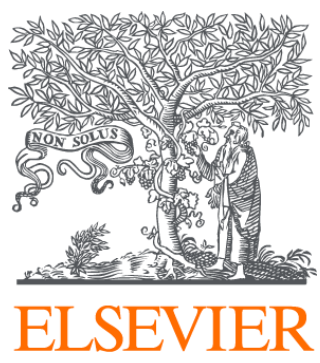

Since January 2020 Elsevier has created a COVID-19 resource centre with free information in English and Mandarin on the novel coronavirus COVID-

19. The COVID-19 resource centre is hosted on Elsevier Connect, the company's public news and information website.

Elsevier hereby grants permission to make all its COVID-19-related research that is available on the COVID-19 resource centre - including this research content - immediately available in PubMed Central and other publicly funded repositories, such as the WHO COVID database with rights for unrestricted research re-use and analyses in any form or by any means with acknowledgement of the original source. These permissions are granted for free by Elsevier for as long as the COVID-19 resource centre remains active. 


\section{INFECTIONS IN DAY-CARE CENTERS}

The first day-care center in the United States opened in 1928 in Boston. From a small beginning, the phenomenon of day care in this country has taken on major proportions. As of 1974, about 5 million children between the ages of 3 and 5 years were estimated to be in licensed day-care centers. The major reason behind this large increase in day-care attendance has been the increased number of families with children in which both spouses work and the increased percentage of one-parent families. In 1969, the number of intact families with children under 6 years of age in which both parents worked was estimated to be about 2.5 million. By 1984, this number was estimated to be 6.2 million. The increase in one-parent families with working mothers has been even higher. At this time, about $90 \%$ of American families use "out-of-home" child care facilities on a full- or part-time basis.

Only in the last 10 years have day-care centers been recognized as significant reservoirs of infection for the children in the day-care center and in the community at large. Our purpose is to summarize present knowledge of infectious diseases that cause significant disease in the day-care center setting or for which the day-care center may serve as a community reservoir. Each section contains information on a specific infectious agent, including pathogenesis, transmission, attack rates, and principles of management. A pull-out, comprehensive table is provided on page $\mathrm{C} 1$ for quick reference (Table 1 ).

\section{CAMPYLOBACTER}

Campylobacter jejuni is a newly recognized cause of gastroenteritis affecting persons of all ages. Recent data from the U.S. suggest that recovery rates of Campylobacter from the stools of persons with enteric symptoms are higher than recovery rates of Salmonella and Shigella combined. ${ }^{19}$ Although this infection is usually acquired from contaminated food or water, interperson transmission by the fecal-oral route can occur, ${ }^{23,30,34,135,176}$ and transmission in the day-care setting has been documented..$^{30}$

Campylobacter jejuni is a spiral, motile, gram-negative rod widely found in nature. Natural reservoirs include many avian species, especially domestic fowl, as well as swine, cattle, sheep, 
horses, rodents, and monkeys. ${ }^{22}$ In addition, domestic animals, particularly puppies, may be infected. ${ }^{20}$ Transmission from infected animals may occur via contaminated food or water or by direct contact. Outbreaks have been reported from improperly treated water supplies and from food sources such as raw milk, uncooked chicken, raw clams, and raw beef. ${ }^{22}$

The manifestations of Campylobacter infections in children range from mild, watery diarrhea to bloody dysentery and high fever. Generally, children with gastroenteritis due to Campylobacter are sicker than those with viral gastroenteritis. Table 2 lists the frequency of clinical findings among children with Campylobacter enteritis in three large studies. ${ }^{54,105,139}$ Diarrhea, abdominal pain, and fever are generally present, and blood is commonly visible in the stool. On occasion, gastrointestinal blood loss may be marked. Some persons may have pain severe enough to mimic generalized peritonitis. Complications of severe Campylobacter enteritis include dehydration, inanition, and blood loss. Reactive arthritis has been reported, especially in persons with the HLA-B27 antigen. ${ }^{160}$ Severity of the illness usually peaks within 3 days. Diarrhea and pain commonly cease within 7 days, although relapses are common. Occasionally, more protracted illness may occur and can lead to the erroneous diagnosis of Crohn's disease or ulcerative colitis. Bacteremia and metastatic focal infections have been described but are relatively rare. The diagnosis of Campylobacter enteritis is determined by stool culture on selective media. An experienced microbiologist can rapidly identify the organism by dark-field ${ }^{140}$ or direct smear ${ }^{141}$ examination of the stool.

Interperson transmission of Campylobacter within households has been well documented. ${ }^{23,34,135}$ Most such outbreaks have occurred in fecally incontinent young children or infants in diapers. Although outbreaks in day-care centers have not commonly been reported in the literature, one of the earliest reports of infection involved a day-care center. In 1972, Cadranel and associates $^{30}$ reported an outbreak of presumed Campylobacter

TABLE 2.

Signs and Symptoms of Campylobacter jejuni Gastroenteritis in Children

\begin{tabular}{lccc}
\hline & $\begin{array}{c}\text { MAYO }^{* 53} \\
(\%)\end{array}$ & $\begin{array}{c}\text { MONTREAL }^{139} \\
(\%)\end{array}$ & $\begin{array}{c}\text { TORONTO } \\
(\%)\end{array}$ \\
\hline Diarrhea & 95 & 100 & 95 \\
Abdominal pain & 89 & 67 & 60 \\
Fever & 78 & 83 & 86 \\
Vomiting & 49 & 37 & 30 \\
Blood in stool & 57 & 51 & 92 \\
\hline
\end{tabular}

*Study included some adults. 
enteritis in a day-care center in Belgium. The index case was a 16-month-old male infant who had diarrhea for over 5 months. During this protracted course, the same infection developed in 14 of 30 other infants and in one adult in the nursery. Diarrhea in the index case ceased when he was given erythromycin to treat an intercurrent respiratory infection.

\section{TRANSMISSION}

As with Salmonella, the interperson transmission of Campylobacter enteritis is probably limited by the sensitivity of the organism to gastric acidity; however, an even higher inoculum of Campylobacter is required to establish infection in a normal host. The incubation period ranges from 1 to 7 days with an average of 3 to 4 days. Symptomatic patients shed $10^{6}$ to $10^{9}$ organisms per gram of stool. ${ }^{22}$ Asymptomatic shedding occurs for several weeks in the untreated patient. After 3 months all untreated patients are usually free of the organism. ${ }^{105}$, 178 Asymptomatic shedding probably does not often transmit disease from person to person. Few data are available concerning the secondary attack rate in closed populations. In the Belgian outbreak, half of exposed infants and children were affected. The general lack of reported outbreaks, however, in contrast to the common occurrence of the illness, suggests a lower secondary attack rate. Presumably, as with other enteric pathogens, the presence of fecally incontinent children and the level of hygiene are directly related to the risk of spread in the day-care setting.

\section{MANAGEMENT}

The day-care center should have a policy that assures it will be notified of all cases of Campylobacter infection that occur in children or adult staff of the facility. Symptomatic persons with Campylobacter enteritis should be excluded from the facility until diarrhea has ceased. Contacts of the index case who are symptomatic should be excluded from the center, and a stool culture should be obtained for Campylobacter isolation.

All symptomatic persons should be treated with erythromycin, $40 \mathrm{mg} / \mathrm{kg}$ for 7 days. The mean duration of stool shedding of Campylobacter after erythromycin therapy begins is 2 days. ${ }^{138}$ Treatment begun after 4 days of illness has no effect on the natural course of the illness. ${ }^{10}$ Because Campylobacter enteritis is apparently not spread by asymptomatic carriers, exclusion or cohorting of such carriers is probably of no value. There is no evidence that prophylactic administration of antibiotics to contacts is effective.

During an outbreak, day-care center staff must use extra care in handwashing and disposal of potentially contaminated diapers. Environmental surfaces used for changing diapers must be 
cleaned frequently with a suitable disinfectant. Toilet-trained children should be supervised during visits to the restroom. Special care must be taken when preparing food to avoid contamination by fecal organisms. During an outbreak parents should be discouraged from transferring children to other day-care centers; this prevents extension of the infection to other facilities. Similarly, new children should not be accepted into the center until the outbreak is over. When feasible, an attempt should be made to identify the source of infection in the index case in order to prevent further outbreaks. Local public health authorities may be of help in this endeavor.

\section{CYTOMEGALOVIRUS}

Children attending day-care centers often have subclinical infections with cytomegalovirus (CMV). ${ }^{142,143}$ Although there is no apparent impact on the health of such children, concern has been expressed about the exposure of female day-care center personnel of childbearing age. The potential for primary infection of susceptible pregnant staff members and the risk of congenital infection in their offspring have not been thoroughly investigated.

CMV is one of the group of herpesviruses. Two or more serotypes of CMV are thought to exist, and a host of genetically distinct strains have been identified using restriction endonuclease analysis of purified viral DNA. ${ }^{95}$ Human CMV infections are thought to be specific to the species.

A wide range of clinical pathology occurs in congenital CMV infection. Effects range from silent infection in most cases to full cytomegalic inclusion disease. Cytomegalic inclusion disease, typified by intrauterine growth retardation and multisystem involvement, occurs in less than $5 \%$ of fetuses infected during gestation.

In a prospective serologic follow-up of 44 children certified to have congenital CMV, Hanshaw and colleagues ${ }^{89}$ identified $16 \%$ as having IQs of less than 79 and $13 \%$ as having bilateral hearing loss compared with none and $2 \%$ of matched controls, respectively.

\section{TRANSMISSION}

CMV can be isolated from a variety of bodily fluids as well as from infected tissues. Viral shedding in urine, saliva, semen, cervical secretions, and breast milk is thought to contribute to the transmissibility of this agent under a number of circumstances involving intimate contact. Viremia accounts for transfusion-acquired cases and congenital CMV infections.

In studies of North American newborns screened by urine culture, congenital infection occurred in $0.42 \%$ to $2.45 \% .{ }^{110}$ The 
majority of intrauterine infections occur after primary infection of susceptible women during pregnancy.

\section{Infections in Day-Carf Centers}

The prevalence of CMV shedding varies from center to center. Rates have been reported well above the prevalence rate of $5 \%$ to $18 \%$ expected among 12 -month-old children cared for in their own homes. ${ }^{57,114,143}$ For example, $57 \%$ of middle-class day-care center infants studied by Pass and co-workers ${ }^{143}$ shed CMV, but the rate reached $78 \%$ in the second year of life. Twenty-three percent of 10- to 14-year-old children were found to be seropositive for CMV. ${ }^{186}$

Pass and co-workers ${ }^{143}$ evaluated the prevalence of CMV in children of seronegative mothers by comparing children who were cared for at home to those who attended day-care centers. Among those receiving home care, only one of $28(3.5 \%)$ had serologic evidence of having been infected. Among those in day care, 11 of $20(55 \%)$ had serologic evidence of CMV infection; in these cases, the seronegative mothers could not have been the source of infection, which was probably contracted in the daycare center.

CMV is most readily isolated from the urine. ${ }^{102}$ It is difficult to isolate from saliva in children over 2 years of age, although it is probably often present in low titer. ${ }^{102,143} \mathrm{CMV}$ has been isolated from toys, and it has been hypothesized that objects shared during play are a major mode of transmission, accounting for rates of CMV shedding that are higher in toddlers than in infants. ${ }^{142,143}$ The tendency to mouth objects and to exchange toys as well as the high prevalence of salivary shedding in toddlers favor such transmission.

Group size as well as the number of exposures per week to other children may also be important. However, Ström ${ }^{168}$ found that 13 of $18(72 \%)$ of children in a day-care center in Sweden were shedding CMV despite small group size (12 or fewer) and low turnover. These high rates of CMV shedding represent the cumulative effects of natal, breast-feeding, and day-care transmission. For children in the U.S. from socioeconomic groups in which at least half the women are seropositive, the minimal rate of natal acquisition is thought to be $6.5 \%$, and congenital infection, $1 \%$. Therefore, about 1 of every 13 children attending day care might be shedding CMV. Higher shedding rates are found in breast-fed infants ${ }^{58}$ and in children of immigrants from nonEuropean countries.

\section{Mode of Transmission From Child to Adult}

Infants with hospital-acquired CMV infections who enter homes in which the mother is seronegative frequently transmit 
the infection to the mother. In one study, the rate of infection in mothers during the first year the infant was home was $47 \%$, compared to $2.4 \%$ in other mothers. ${ }^{193}$ In general, studies of seronegative pediatric nurses have not indicated that they are at increased risk of acquiring CMV infections compared with controls, ${ }^{8,57,110,192}$ although certain subgroups such as intensive care nurses and phlebotomists may have an increased risk. ${ }^{66}$ The mode of transmission is not known but is presumed to require close contact. Airborne transmission is probably not important in spreading CMV.

Over half of middle-class women are susceptible to CMV during the childbearing years. ${ }^{186}$ Over $45 \%$ of the staff of day-care centers are seronegative, although rates may vary among centers. ${ }^{102}$ The potential for transmission from the child to the mother or to the day-care staff is high, but the actual risk is still being studied and is not yet known. Exposure of day-care staff to CMV is not higher in centers for the developmentally disabled infant than in centers for normal infants. ${ }^{102}$

\section{Prevention of CMV Infection Among Day-Care Center PERSONNEL}

Exclusion of children known to shed CMV has no place in the prevention of this problem. In fact, identified cases theoretically represent less of a threat than the large number of children who are not known to be infected, because personnel are more likely to comply with appropriate precautions in caring for known cases.

At present, the most practical method of preventing CMV infections among susceptible day-care center employees is through education about the potential hazards of congenital CMV infection and about modes of its transmission and prevention. Encouraging handwashing after diapering and after handling children's secretions and mouthed objects is probably the single most practical means of prevention at present. Encouraging improved physical facilities with adequate numbers and placement of sinks or lavatories and advocating the use of disposable towels and diapers are general measures helpful in preventing a variety of infectious diseases.

Once a safe and effective vaccine becomes available, day-care center employees may be ideal candidates for CMV immunization. Until that time, common sense and good hygiene constitute the main means of preventing this ubiquitous infection.

\section{VIRAL GASTROENTERITIS}

Day-care centers have been implicated as settings for the spread of communicable diseases, especially diarrhea. Children less than 3 years of age in day care can be expected to have an 
average of 1.24 episodes of diarrhea per child per year. ${ }^{169} \mathrm{Al}$ though several outbreaks due to bacterial and parasitic agents have been reported in day-care centers, it has only recently been recognized that rotavirus is a major cause of diarrhea in children under 2 years of age in day care. ${ }^{108}$

In 1942, Hodes ${ }^{92}$ isolated a filterable virus from an outbreak of diarrhea among newborn infants. Not until 1973, however, did Bishop and associates ${ }^{16}$ characterize what were later classified as the rotaviruses. There are at least three distinct serotypes of rotavirus, and type 2 is responsible for the most serious disease.

In addition to rotavirus, other viruses have been recognized as a cause of gastroenteritis. The Norwalk virus is a small parvovirus that has been responsible for outbreaks of gastroenteritis among children and adults. Disease due to parvoviruses has been almost uniformly mild and has tended to occur primarily in children of school age or older. Diagnosis is by immunoelectron microscopy of stool specimens. Adenoviruses, too, are an uncommon cause of diarrhea in childhood. Other uncommonly reported viral causes of diarrhea in children include the coronavirus, astrovirus, calicivirus, and minirotavirus. Outbreaks due to these agents have been reported in children and adults. Although enteroviruses have been isolated in association with several outbreaks of diarrhea in children, causation is difficult to establish because enteroviruses are frequently isolated from the stools of symptomatic children. The role of the Norwalk agent, adenovirus, coronavirus, astrovirus, calicivirus, and minirotavirus as a cause of diarrheal disease in children in day-care centers remains unknown. ${ }^{159}$

\section{EPIDEMIOLOGY}

In developed countries, rotavirus is the most common cause of diarrhea in infants and children. Rotavirus diarrhea is more common in winter than in summer, although it can occur yearround. Infants and children under 5 ycars of age are most susceptible to rotavirus diarrhea, although outbreaks of disease in adults have also been reported. Rotavirus infection is relatively contagious. Approximately $10^{10}$ virus particles may be shed per gram of stool, and asymptomatic shedding also may occur. ${ }^{165}$ In one reported outbreak due to type 2 rotavirus, the infection not only affected all nine infants in a play group but also seven of ten parents and grandparents studied. ${ }^{155}$ The spread of rotavirus in the day-care setting is enhanced by the relative stability of the virus on inert surfaces such as toys and tabletops. Rotavirus is stable for 30 minutes on a dry surface and for much longer when suspended in fecal material. ${ }^{108}$

The incubation period of gastroenteritis due to rotavirus is 1 to 3 days, and symptoms of vomiting and diarrhea usually begin 
abruptly. The mean duration of diarrhea is 5 days. The disease is usually self-limiting, but fatalities due to dehydration and shock have been reported. The diagnosis can be made either by electron microscopy of stool specimens or by enzyme linked immunosorbent assay. ${ }^{155}$

\section{RECOMMENDATIONS}

Although viral gastroenteritis, especially that due to rotavirus, is the most common cause of gastroenteritis in the day-care center age group, formulating specific recommendations is hampered by the fact that the parents, day-care center operator, and physician are usually unaware of the specific cause of viral gastroenteritis. Although a commercial test is now available for detecting rotavirus in stool, this test is relatively expensive and infrequently used in the clinical practice of pediatrics. Tests for the other viral causes of gastroenteritis are available at research centers only. Thus, recommendations must be directed toward the management of presumed viral gastroenteritis, recognizing that rotavirus probably accounts for most cases.

The most important factor in preventing outbreaks of viral gastroenteritis is careful handwashing on the part of the daycare center staff. Black and colleagues ${ }^{17}$ demonstrated that the incidence of diarrhea in a day-care center was halved after introduction of a handwashing program. Handwashing is especially important after changing diapers and before handling food. Moreover, the risk of a diarrhea outbreak is greatly reduced if separate caretakers are responsible for food handling and diaper changing and if these two activities occur in separate locations. ${ }^{117}$ Because shared toys can very effectively carry the infectious agent from one child to another, sharing toys must be limited among children who are not yet toilet trained. Where such sharing is unavoidable, a regular program of disinfecting these toys should be instituted.

Once an outbreak of viral gastroenteritis has occurred, children with diarrhea should be sent home from day care until they are well. The day-care center should have a policy requiring that the parents report to them if a child is home with gastroenteritis, and the child should be seen by a physician for evaluation of possible bacterial, parasitic, and viral causes of diarrhea. Parents of contacts of the index case should be notified that their child has been exposed to a case of gastroenteritis and that all children in whom diarrhea develops should be excluded from day care until they are asymptomatic. If several children in a multiroom facility become ill, the remaining children should be separated into cohorts, so that there is minimal contact between the staff and children of those rooms remaining disease-free and those with infected children. During an outbreak of viral gastroenteritis, extra precaution should be laken to assure that 
careful handwashing and diaper-changing techniques are being practiced. If the outbreak persists, the assistance of the local public health department should be sought.

\section{GIARDIASIS}

At one time, Giardia lamblia was not considered a pathogen in man. However, after reports of epidemics in travelers to the Soviet Union in 1971, Giardia was recognized as a major cause of diarrhea in travelers and a cause of waterborne disease outbreaks in the U.S. ${ }^{191}$ In 1977 , a day-care center outbreak led to the recognition that interperson transmission of the infection also can occur. ${ }^{18}$ Giardiasis is now recognized as an endemic problem in the day-care setting, and day-care centers may form a major reservoir for this parasite. ${ }^{162}$

G. lamblia is a flagellate having both a cystic and trophozoite stage. The organism has two nuclei and four flagella and is about $15 \mu$ long. Giardia inhabits the duodenum and upper jejunum, where the $\mathrm{pH}$ is alkaline. The trophozoites attach firmly to the intestinal wall but may also exist in free form. The infection is passed by the ingestion of cysts in fecally contaminated food, water, or other objects.

Giardia infection, especially in young children, may be asymptomatic. In patients with acute symptoms, there is usually a 15-day incubation period, followed by diarrhea, belching, headache, and malaise. Distention and flatus are characteristic. The acute stage usually lasts for 4 days and resolves, or the disease may progress into a subacute or chronic form that may last for months. Patients may also become asymptomatic carriers. ${ }^{190}$

Diagnosis in the early, acute stage of the symptomatic infection is by stool examination. Studies of the prevalence of Giardia in day-care centers suggest that analysis of stool specimens can identify most children with symptomatic infection due to Giardia and can also identify many asymptomatic carriers. Studies in adults indicate that analysis of three stool specimens can identify $97.6 \%$ of symptomatic persons with Giardia. In the case of negative stool examinations in an asymptomatic child, it may be necessary to resort to analysis of duodenal fluid either by direct aspiration or by use of the Enterotest ${ }^{\circledR} . * 190$

\section{EPIDEMIOLOGY}

Several studies indicate that $G$. lamblia is common in the daycare setting and that day-care centers may be a major community reservoir for Giardia. In 1975, Black and colleagues, ${ }^{18}$ reporting on three day-care centers, found prevalence rates for Giardia that ranged between $29 \%$ and $54 \%$. These rates con-

\footnotetext{
${ }^{*}$ Enterotest ${ }^{\circledR}$ : HDC Corporation, Mountain View, California.
} 
trasted with a $2 \%$ prevalence rate among children not in day care. The presence of Giardia in the stool was significantly associated with a history of diarrhea of 10 days or longer, flatulence, and bloating. The authors noted, however, that the children ranged between asymptomatic shedders and children with frank malabsorption and weight loss. In a community-wide study, Sealy and Schuman ${ }^{162}$ reported that the attack rate for children in day care was $26 \%$, and that children who had been in day care entered first grade with six times as much infection as children who had been cared for at home. The authors further estimated that as few as 100 infected children in day care could maintain Giardia at endemic levels of infection in a county of 18,000 residents. In another recent study of Giardia in day care by Pickering and co-workers ${ }^{147}$ Giardia cysts were identified in $21 \%$ and $26 \%$ of children in two day-care centers. Trophozoites were identified in $4 \%$ of children. No correlation was found between the frequency of recent diarrheal episodes and the finding of Giardia. The recovery of cysts was low during the first year of life and reached a peak in 19- to 24-month-old children. Children who had attended day care for more than 6 months had a greater frequency of cysts in their stools than children who had attended for less than 6 months. In the same study, ${ }^{147}$ Giardia was found in stool specimens collected from 12 children each week for a mean of 6 months (range, 2 to 14 months). Thus, the infection may last a relatively long time in some children. Neither the number of enteric symptoms observed nor nutritional status differed significantly between infected and noninfected children. Pickering and co-workers ${ }^{147}$ concluded that asymptomatic Giardia infection in children less than 3 years of age attending day-care centers is common and appears to be well tolerated.

\section{RECOMMENDATIONS}

Day-care centers should notify the parents of children who have been in direct contact with a child infected with Giardia. The parents should be told that a child in the center is infected, and advised to call their physician for advice if their child develops diarrhea, mushy stools, or flatulence. Routine testing for Giardia among case contacts within the group is not indicated. Children who have had symptomatic Giardia infection may return to day care after treatment when diarrhea is no longer present. Routine retesting of these children by stool examination before reentry is not recommended. Children who are asymptomatic carriers of Giardia infection should not be treated, as they grow normally and are apparently unharmed by the infection. ${ }^{154}$ Furthermore, screening day-care center populations for these children is expensive, and there is no evidence that Giardia can be eradicated from a day-care center by screening and treating 
asymptomatic children with presently available chemotherapeutic agents. The combined problems of questionable safety, poor tolerance, relative lack of efficacy, and the cost of available treatment agents make it inadvisable to treat asymptomatic children.

Handwashing technique in the day-care center must be rigorously enforced, and day-care center employees must not use tables used for changing diapers to handle and prepare food instead. Studies of diarrhea from all causes in the day-care setting have shown that the incidence of diarrhea can be reduced by half with adequate handwashing alone. Proper handwashing protects not only the children but also the staff of the day-care center.

\section{HEMOPHILUS INFLUENZAE, TYPE B}

Although Hemophilus influenzae, type B (HIB) has been recognized as a major human pathogen for almost a century, the epidemiology of infection due to this pathogen has only recently become well understood. Disease due to HIB affects people of all ages and has a broad clinical spectrum. HIB is the leading cause of bacterial meningitis in childhood and accounts for 8,000 cases in the U.S. each year. ${ }^{65}$ In addition, HIB is responsible for an undetermined number of cases of septicemia, epiglottitis, pneumonia, arthritis, and cellulitis each year. The case fatality rate for all forms of bacteremic disease due to HIB has been estimated to be $3 \%$ to $7 \%$, and about $10 \%$ of those recovering from meningitis are left with permanent neurologic sequelae. ${ }^{77} \mathrm{Al}-$ though invasive disease due to HIB can occur at any age, nearly $95 \%$ of cases occur in children less than 5 years old. ${ }^{74}$ Thus, preschool children are at highest risk for invasive disease, whether or not they attend day care. However, it has recently become apparent that secondary cases of invasive disease due to HIB occur more commonly among household contacts of children with invasive HIB disease and in day-care centers where an initial case of invasive disease has occurred. ${ }^{100,174}$ A national cooperative study has demonstrated that rifampin is an effective prophylactic agent for preventing secondary cases of HIB disease among household contacts of persons with meningitis due to HIB, but efficacy of rifampin prophylaxis in the day-care center setting remains controversial.

\section{EPIDEMIOLOGY}

Age-specific episode rates of HIB meningitis are highest in children less than 1 year of age and decrease steadily thereafter. Until recently, the quantitative risk of secondary spread of HIB in households and through other close contact was unknown, although there were early reports of familial and institutional 
spread of disease. ${ }^{13}$ Within the last 5 years, the increased risk of secondary spread of disease among household contacts, institutionalized children, and children attending day-care centers has been recognized. In a national multicenter study, ${ }^{180}$ the risk of a secondary case of invasive disease due to HIB among household contacts of children with meningitis due to HIB was greater than that in the general population. This risk was age-dependent (Table 3): household contacts less than 1 year of age had a $6.0 \%$ risk of disease, whereas the risk decreased to $0.1 \%$ by 4 years of age. The risk of a secondary case in a household, regardless of age, was $0.21 \%$, which is comparable to the risk of secondary cases of disease due to meningococci. ${ }^{180}$ In that study, the period of risk for developing a secondary case was arbitrarily defined as 30 days or less. The exact period of risk is not known.

Although there is general agreement about the level of risk of secondary disease among household contacts, there has been controversy regarding the level of risk in day-care center contacts. Data from different studies on the age-specific risk for disease in day care are contradictory, but nearly all reported cases have occurred in children less than 4 years of age, most in infants less than 2 years of age. ${ }^{75}$ The development of secondary cases in a day-care center may be rapid, and several cases may develop within 1 week. Furthermore, an outbreak may last 6 months or longer. ${ }^{75}$ Carriage rates during an outbreak have been observed to have a wide range. Although carriage rates are higher in centers where two or more cases of disease develop compared with centers where only one case develops, there is no direct correlation between carriage rates among contacts and risk of disease. ${ }^{181}$ The inconsistent relation between colonization rates and disease may result from varying pathogenicity among strains of HIB. Isolates of HIB with a distinctive outer mem-

TABLE 3.

Risk of Secondary Invasive Disease Among Household Contacts*

\begin{tabular}{cccc}
\hline $\begin{array}{c}\text { AGE OF CONTACT } \\
\text { (MO) }\end{array}$ & NO. AT RISK & NO. $\mathrm{LL}^{\dagger}$ & $\begin{array}{c}\text { RISK } \\
(\%)\end{array}$ \\
\hline $0-11$ & 50 & 3 & 6.0 \\
$12-23$ & 69 & 1 & 1.4 \\
$24-47$ & 259 & 4 & 1.5 \\
$48-71$ & 1,309 & 1 & 0.1 \\
$\geq 6$ years & 2,624 & 0 & 0 \\
Total & $\mathbf{4 , 3 1 1}$ & $\mathbf{9}$ & $\mathbf{0 . 2 1}$ \\
\hline
\end{tabular}

*Adapted from Ward JI, et al: $N$ Engl J Med 1979; 301:122126. Used by permission.

†ontacts who contracted systemic HIB disease within 30 days on onset of illness in index case. 
brane protein subtype designated $1 \mathrm{H}$ may be more pathogenic than other strains.

Differences among day-care centers may also affect the risk of secondary HIB disease. Because the risk of secondary cases appears to be highest in children less than 2 years of age, children in day-care centers with a high proportion of children in that age group have a proportionately higher risk of secondary disease. Centers that have a stable, small population have less risk of introducing HIB than centers that take children on a drop-in basis and have a large, unstable constituency.

\section{CHEMOPROPHYLAXIS}

Since recognition of the risk of secondary disease due to $\mathrm{HIB}$, various chemoprophylactic regimens have been tried with the goal of preventing secondary disease ${ }^{14}$ Because of the difficulty in conducting studies that assess the efficacy of therapeutic regimens for eradicating secondary disease, most studies have concentrated on the effect of various antibiotic regimens for eradicating carriage.

In direct analogy with the efficacy of rifampin for eradicating carriage with meningococci, rifampin has been found uniquely effective for eradicating carriage of HIB. Other anti-infective agents, such as ampicillin, cefaclor, trimethoprim-sulfamethoxazole and erythromycin-sulfamethoxazole, have not been effective. ${ }^{48}$. The efficacy of rifampin is believed to be due to the high levels of this agent attained in oral secretions in contrast to other agents. One study ${ }^{13}$ conducted within a day-care center demonstrated that rifampin, $20 \mathrm{mg} / \mathrm{kg}$ daily for 4 days (maximum daily dose, $600 \mathrm{mg}$ ), was approximately $90 \%$ effective for eradicating carriage in children and adults in the day-care center.

A combined study ${ }^{76}$ of HIB infections in day-care and household settings tested the efficacy of rifampin in reducing secondary disease due to HIB. In that national cooperative trial, 1,940 children who were contacts of a child with invasive disease due to HIB were randomized to receive either placebo or rifampin. In the group of 839 children who received placebo, four cases of secondary invasive disease occurred, three among household contacts and one in a day-care center contact. None of the 1,101 children who received rifampin prophylaxis developed secondary disease. This study has been the basis for recommending rifampin prophylaxis for household contacts in invasive HIB disease. However, since the number of cases of disease in the study was small, no conclusion can yet be reached on the efficacy of rifampin prophylaxis in the day-care setting.

Furthermore, although some analyses of outbreaks in day care have failed to demonstrate any beneficial effect of rifampin on 
the incidence of secondary disease due to HIB, a recent multicenter study ${ }^{126}$ showed that the risk of classroom contacts was similar to that of household contacts and that rifampin was effective when a compliance level of $75 \%$ or higher was attained. Specifically, the age-related risk for all classroom contacts was $2.4 \%$ in day-care contacts 0 to 11 months of age, $1.2 \%$ in those 1 to 2 years of age, and did not exist above that age. In an analysis of 150 primary cases, 10 secondary cases occurred among 1,300 classroom contacts. All secondary cases occurred in day-care centers in which there was less than $75 \%$ compliance with the rifampin regimen. Furthermore, all the secondary cases occurred in children who had not taken rifampin.

The American Academy of Pediatrics Committee on Infectious Diseases ${ }^{46}$ has recently revised its recommendations on the use of rifampin prophylaxis for HIB in day care by recommending that it only be instituted after two consecutive cases. Murphy and associates ${ }^{127}$ demonstrated that three attempts at rifampin prophylaxis were unsuccessful in eradicating carriage due to HIB. During two attempts at prophylaxis, $39 \%$ and $60 \%$ of the infants, respectively, did not receive rifampin. In a third attempt at prophylaxis coordinated directly by the investigators, five of nine infants remaining in the day-care center were recolonized with the initial invasive strain 2 weeks after rifampin prophylaxis. Moreover, a nontypable $H$. influenzae strain resistant to rifampin was isolated from one child. That study demonstrated not only the difficulty of successfully coordinating chemoprophy. laxis within the day-care center setting but the potential for emergence of strains resistant to rifampin. Expense is another problem: the cost of rifampin prophylaxis for the average-sized family has been estimated to be $\$ 55$. Several authors ${ }^{50,}{ }^{27}$ have recommended that rifampin prophylaxis be undertaken in the day-care center setting only if a high level of compliance can be assured and only after a second case has occurred within the day-care center.

\section{VACCINATION}

A vaccine for HIB has recently been licensed for use in the U.S. This vaccine is more than $95 \%$ effective in inducing a protective level of antibody in recipients 2 years of age or older. However, the vaccine is not effective in children less than 18 months of age. It induces a protective level of antibody in $60 \%$ to $80 \%$ of children between 18 months and 2 years of age. The vaccine is presently recommended for routine administration to children age 2 years and older and should also be considered for those 18 months of age and older who are in day care. An additional dose of vaccine may be required for children who were vaccinated between 18 and 24 months of age..$^{5,47}$ 


\section{RECOMMENDATIONS}

Routine vaccination with HIB vaccine should be required for all children in day care who are 2 years of age and older. Immunization of infants between 18 months and 2 years of age should also be encouraged in larger day-care centers.

The day-care center should have a policy of notifying all parents of children in the center of invasive cases of disease due to HIB. Because neither vaccination nor chemoprophylaxis can be assumed to be $100 \%$ effective when they are undertaken, parents should be advised to seek medical attention if their child becomes ill, whether or not that child has received prophylaxis.

The indications for rifampin prophylaxis in the day-care setting remain controversial. Studies of chemoprophylaxis in day care have focused on larger day-care centers, emphasizing the difficulty in coordinating rifampin prophylaxis in such centers and its subsequent failure. Because of these reports, it is recommended that prophylaxis be undertaken in the day-care center after the first case of invasive disease due to HIB in the center only if: (1) the center is small (fewer than 10 children); (2) the percentage of children in the age group at greatest risk within the center is high (less than 2 years of age); and (3) good compliance with concurrent administration of rifampin to daycare attendees and caregivers can be assured. In the case of larger day-care centers or centers caring for children predominantly older than 2 but less than 4 years of age, rifampin prophylaxis should be considered only after a second case of invasive disease due to HIB has occurred in the day-care center and if $75 \%$ or more compliance with the rifampin regimen among staff and children can be reasonably assured.

For the purpose of chemoprophylaxis, a day-care center contact is arbitrarily defined as a child who has spent more than 1 day per week or 10 hours per week in the same room as the sick child. In order to prevent "ping-ponging" of the infection, all contacts and staff should receive rifampin prophylaxis concurrently (at the same time or within 3 days). All children who have been ill with HIB must receive rifampin prophylaxis before returning to the day-care center, regardless of any other antibiotic therapy received. If more than 3 weeks elapse after a case of invasive disease due to HIB has occurred within the day-care center, rifampin prophylaxis should not be given. Finally, no evidence exists that friends of children in the day-care center who do not attend the center need to be treated.

Rifampin is available only in $300-\mathrm{mg}$ capsules but will soon be released in 150-mg capsules. The dose for a child can be prepared in suspension by a pharmacist or given in small amounts of food such as applesauce. A dosage of $20 \mathrm{mg} / \mathrm{kg}$ daily should be given orally for 4 days (maximum daily dose, $600 \mathrm{mg}$ ). The safety of rifampin in pregnancy has not been demonstrated. Pa- 
tients should be advised that rifampin will turn urine orange and may stain soft contact lenses. Furthermore, rifampin may interfere with the efficacy of oral contraceptives, and alternative methods of contraception should be considered during the remainder of the menstrual cycle of women receiving rifampin prophylaxis.

Whether or not rifampin prophylaxis is undertaken, parents of children in day-care centers in which an initial case of invasive disease due to HIB has occurred should be advised to seek medical attention promptly if their child becomes febrile or ill.

\section{HEPATITIS A INFECTION}

Although evidence appeared in the late 1930s that hepatitis A virus (HAV) can spread in classrooms, only in the mid-1960s did hepatitis A become appreciated as a major potential health problem associated with day-care centers. A substantial portion of hepatitis A cases in the community are now believed to originate from asymptomatic cases or outbreaks in day-care centers.

\section{BACKGROUND}

Hepatitis A virus is a picornavirus that causes acute, nonspecific febrile illness characterized by jaundice, nausea, diarrhea, anorexia, and malaise. The infection is asymptomatic in infants and preschool children in $90 \%$ of cases. In about $50 \%$ of older children, 4 to 6 years of age, and in 75\% of infected adults, clinical illness with jaundice develops. Rarely, the disease can be fulminant and fatal. Chronic sequelae or a chronic carrier state is not associated with HAV infection.

Infection with $\mathrm{HAV}$ is acquired at a younger age in developing countries and among lower socioeconomic groups rather than in middle or upper socioeconomic populations in the U.S. ${ }^{53,120}$ By the fifth decade of life, $80 \%$ of the U.S. population has antibodies to HAV.

The incubation period for HAV is from 15 to 40 days, and the period until the onset of jaundice ranges from 25 to 30 days. As with other enteric viruses, a brief period of viremia occurs up to 25 days before the onset of jaundice. Although parenteral infection by blood transfusion or percutaneous route can be transmitted during this viremic stage, the usual method of interperson transmission of HAV is by the fecal-oral route. Common source foodborne and waterborne outbreaks also can occur. Infected persons are most likely to excrete and spread the virus during the two weeks immediately preceding the onset of jaundice, and the highest titers of HAV in stool are found just before liver enzymes become elevated. The exact period of contagiousness is uncertain but is probably minimal during the week after the onset of jaundice. However, in certain persons, such as homosex- 
uals and ill, premature infants, the duration of viral shedding in the stool may be longer.

Specific serologic tests for HAV are commercially available. The presence of IgM anti-HAV indicates a recent infection, whereas that of IgG anti-HAV alone indicates past infection and immunity. Detection of HAV particles in the stool by immunoelectron microscopy can be done in research or special public health laboratories, but this is seldom necessary in routine clinical settings.

\section{Epidemiology of HAV Infection in Day-Care Centers}

The risk of a hepatitis outbreak in a day-care center is related to the characteristics of the center, the number of susceptible children and adults associated with the center, and the prevalence of hepatitis A in the community. Seroprevalence studies indicate that more than $90 \%$ of children from middle and upper socioeconomic classes and more than $50 \%$ of young adults may be susceptible to HAV as defined by lack of antibodies to HAV. Therefore, the "population at risk" can be sizable.

Detailed studies and reports of separate outbreaks of HAV infections occurring a day-care centers throughout the U.S. during the mid-1960s to the end of the $1970 \mathrm{~s}^{81,83,166,188}$ have laid the foundation of our knowledge regarding the magnitude and the public health aspects of HAV infection in day-care centers. For example, in 1977 in Maricopa County, Arizona, more than 40\% of reported cases of hepatitis A or viral hepatitis of unspecified type occurred in persons closely associated with day-care centers. ${ }^{83}$ of the 279 licensed centers studied, $85(30 \%)$ had outbreaks of hepatitis affecting three or more families. ${ }^{81}$ The duration of outbreaks averaged 11 weeks and ranged from 2 to 36 weeks. ${ }^{69,162}$ Hepatitis outbreaks in day-care centers therefore have major impact on the community at large.

The following epidemiologic features have been recognized: (1) Because HAV infection in preschool children is usually asymptomatic or causes only mild, nonspecific symptoms, the spread of hepatitis in day-care centers is usually not recognized until clinical infection occurs in center employees or household contacts of attendees. In the Maricopa County study, ${ }^{83}$ hepatitis rates were highest for the employees (121 cases per 1,000 at risk) and were lower for household contacts (40 cases per 1,000) and center attendees (22 cases per 1,000). (2) Contacts (parents, siblings, center employees) of children less than 2 years of age are at highest risk for secondary hepatitis illness. Of family contact cases, $76 \%$ occurred in persons whose child was less than 2 years of age; of employee cases, $72 \%$ occurred in those who worked with children in diapers; these employees had an attack rate four times higher than those who worked with older children. (3) The most significant risk factor for the occurrence of out- 
breaks is the minimum age of children in the center. In the Maricopa County study, outbreaks occurred in $63 \%$ of centers that enrolled infants as well as older children, in $32 \%$ of centers with children 1 year of age or older, in $4.6 \%$ of centers with children 2 years or older, and in no centers with children 3 years or older $(P<0.001)$. The other factors that correlate with increased risk of outbreaks include larger size of center (enrolling $>51$ children), number of hours of operation per day ( $>15$ hours), and type of ownership of the center (for profit operation). The presence of drop-in or indigent children, poor hygienic practices, and inadequate staffing in a center do not seem to significantly affect the occurrence of outbreaks.

In summary, the major characteristic of hepatitis A outbreaks in day-care centers is the central role that young infants and toddlers in diapers play in spreading HAV to each other, to the center staff, and to their family contacts. Large centers that provide care for these infants are at highest risk for hepatitis outbreaks. Preschools that do not provide care for children in diapers are at little risk. These findings provide a practical approach to controlling the problem of spread of hepatitis.

\section{Prevention and Management of HaV Infection In Day- CARe Centers}

Prevention and control of HAV infection in day-care centers depend on several factors: emphasis on hygienic and environmental standards; education of staff and parents; maintenance of hepatitis surveillance to detect outbreaks early; and use of immune globulin to prevent secondary spread of hepatitis.

The emphasis on hygienic and environmental standards follows the principles of prevention and control of enteric diseases spread by the fecal-oral route: conscientious handwashing; hygienic procedures for diaper changing and disposal; helping the children with handwashing before meals and at the toilet; proper handling and storage of food and drinks. The hepatitis A virus has been shown experimentally to remain infective for at least 30 days under conditions simulating typical environmental exposure. ${ }^{121}$ The use of germicidal chemicals such as sodium hypochlorite or iodophors is recommended for routine cleaning of areas such as diaper-changing tables and bathrooms or sinks.

Parents and staff at day-care centers should be given basic information on transmission and recognition of hepatitis, and they must be instructed to report to their physicians or to the public health department any early symptoms compatible with HAV infection. When such a case is detected, the diagnosis by IgM anti-HAV must be confirmed quickly to allow earliest possible detection and/or prevention of an outbreak. Because infants are often infected asymptomatically, those immediately cared for by the adult index case (staff or parents) should be 
suspected of being either potential sources of outbreak or incipient secondary cases. The center should immediately phone the local public health department if a hepatitis case is recognized in a day-care attendee or employee or in a parent or sibling of a day-care child. An outbreak can be much more successfully investigated and controlled by public health authorities than by private physicians.

When given within 2 weeks of exposure, immune globulin has been shown to be $80 \%$ to $90 \%$ effective for preventing HAV in exposed persons ${ }^{6}$ and for controlling the spread of HAV within day-care centers as well as from day-care families into the community. ${ }^{82}$ The recommended dose for immune globulin is 0.02 $\mathrm{ml} / \mathrm{kg}$ intramuscularly. Strategies for its use depend on: (1) whether the center accepts children in diapers; (2) in whom the cases of HAV infection are occurring; and (3) how many cases have already occurred. ${ }^{43,177}$

For centers that do not accept children in diapers, the risk of spread is small and the chance of a large outbreak is minimal. In these centers, if a case occurs in a center employee or child, immune globulin is recommended for all the staff and for the children who have been in direct contact with the index case, i.e., those children cared for in the same room as the index case.

In centers that accept children in diapers, the chance of spread after even a single case of $\mathrm{HAV}$ infection may exceed $50 \%$. If cases are recognized in one or more center children, in one or more employees, or in a household contact in two families, immune globulin should be given to all center employees and to all center children, including new admissions, until 6 weeks after the last case at the center.

If, however, the outbreak is recognized late (i.e., more than 3 weeks after the onset of the first case) and cases are recognized in two or more household contacts of center children from two or more families, immune globulin should be considered not only for all center attendees and employees (including new admissions) but also for all household contacts of children aged 3 or less at the center until 6 weeks after the last case at the center.

When immune globulin is indicated, it should be provided at the day-care center to all children and staff concurrently, as this promotes prompt and complete coverage as well as cooperation by parents and center directors in outbreak control. It is not advisable to close a center because of a hepatitis A outbreak or to withdraw children from the center during the outbreak, since this would permit transmission of hepatitis A to other facilities.

\section{MEASLES}

Measles, an acute viral illness, is characterized by fever, catarrhal symptoms, conjunctivitis, rash, and a typical enanthema, Koplik's spots. Since the introduction of measles vaccine, 
this once common childhood disease has been reduced to record low levels in the U.S. Occasional outbreaks continue to occur, mostly in preschool children and college students. ${ }^{39}$ Although several day-care center outbreaks of measles have been reported in recent years, ${ }^{22,33,36,37}$ day-care centers have not been implicated as major foci of measles propagation. This low rate is presumably the result of regulations in more than $90 \%$ of states requiring age-appropriate immunization for preschool children attending licensed group day-care centers. ${ }^{42}$ Current immunization procedures result in about $95 \%$ seropositivity among recipients.

\section{TRANSMISSION}

Measles virus is shed in respiratory secretions. Transmission may be by hand contact with large droplets or by inhalation of secretions in aerosol form. Airborne transmission may occur even in the absence of infectious persons when virus particles remain suspended in closed spaces. ${ }^{153}$

The incubation period of measles ranges from 8 to 18 days. The disease is communicable during the febrile period of illness, generally beginning 4 days before the onset of rash.

Natural immunity to measles does not exist: in $90 \%$ of all susceptible persons, clinical illness develops after exposure. Newborns and young infants may be protected by passively acquired maternal antibodies that almost entirely disappear by 13 months of age. ${ }^{194}$

\section{MANAGEMENT}

When a single case of measles is recognized in a day-care center, the index case should be excluded for 1 week from the onset of illness or for the duration of fever. The local health department should be promptly notified by the diagnosing physician.

The local health department (with the assistance of state and federal agencies as needed) generally implements control measures. The first step in this process is to identify exposed susceptible persons; those born after 1957 without one of the following should be considered susceptible: (1) documented physiciandiagnosed measles; (2) laboratory evidence of measles seropositivity; or (3) documentation of immunization with live measles virus vaccine on or after the first birthday. Persons immunized before 1968 with an unknown type of vaccine may have received killed virus and should be considered potentially susceptible to atypical measles. ${ }^{3}$

Exposed children over 15 months of age and young adults should be immunized if their immune status is questionable. In the day-care center, this goal is most efficiently accomplished by 
excluding those susceptible from the center until documentation of immunization is provided or until 14 days has elapsed since exposure. Persons with medical or personal reasons for not receiving immunization must be excluded. Live measles immunization given within 72 hours of exposure may protect against infection.

Febrile illness occurring during the 2-week observation period should be considered potential measles. Persons with such illness should be excluded for the duration of fever regardless of their immunization status.

Children less than 12 months old who are exposed to measles should receive human immunoglobulin $(0.25 \mathrm{ml} / \mathrm{kg})$. Children 12 months of age or older may be protected if vaccine can be offered within 72 hours of exposure. In children exposed more than 3 days earlier, human immunoglobulin $(0.25 \mathrm{ml} / \mathrm{kg})$ may provide protection or modify the disease. Routine use of immunoglobulin in preventing outbreaks is not recommended, although it may be appropriate in managing contacts less than 12 months of age, who are most likely to develop severe or complicated measles.

Active measles immunization should be delayed at least 3 months after administration of immunoglobulin to permit dissipation of passively acquired antibodies. In addition, immunization should be delayed until the patient reaches 15 months of age.

Measles outbreaks in a community have been used to justify immunization of children as young as 6 months of age. ${ }^{3}$ However, this recommendation is controversial: at least two studies have demonstrated poor serologic response to primary vaccination and revaccination attempts in children initially receiving measles vaccine at less than 1 year of age ${ }^{116,187}$ Thus, individual contacts less than 12 months of age are probably best managed by immunoglobulin administration. Immunization of younger children in a community should be considered when initial attempts to contain the outbreak fail.

Day-care centers can take measures to prevent measles outbreaks by requiring strict compliance with routine immunization procedures. The immunization status of all attendees must be reviewed annually, and new entrants must be required to have documented age-appropriate immunization. The day-care center staff should also be adequately immunized. The day-care center policies must incorporate the need for prompt reporting of suspected measles.

\section{MENINGOCOCCUS}

Outbreaks of invasive disease caused by the gram-negative diplococcus, Neisseria meningitidis, may occur in overcrowded 
living quarters. Such outbreaks have occurred among U.S. military recruits and have been described more recently in day-care centers. ${ }^{64,101,103}$ Among known serogroups, most recent U.S. cases of meningococous infection have been caused by serogroups B (56\%), C (29\%), $7(11 \%)$, W135 (10\%), and A (3\%). ${ }^{12}$ Cases occur endemically and in sporadic localized epidemics. The greatest incidence of disease occurs in the winter and early spring.

Manifestations of invasive disease caused by $N$. meningitidis include septicemia with or without meningitis, pyogenic arthritis, pericarditis, myositis, and pneumonia. Systemic infection may cause disseminated intravascular coagulation, shock, and death. Infected children with peripheral ecchymotic or purpuric lesions have a higher incidence of fulminant disease and death. ${ }^{175}$ Late complications include mental retardation, cerebral palsy, and deafness.

The primary attack rate for meningococcal disease is approximately one case per 100,000 population per year. ${ }^{12}$ Age-specific rates are 14.4/100,000 for infants less than 1 year of age and 4.6/100,000 for children 1 to 4 years. In 1975, the Centers for Disease Control investigated three cases of meningococcal meningitis occurring within 2 weeks in a day-care center in Georgia. ${ }^{101}$ Two similar outbreaks had earlier been reported from Florida. ${ }^{64,103}$ These outbreaks of secondary disease were similar in that "overcrowding" of infants and children was noted by the investigators.

\section{TRANSMISSION}

Interperson spread of meningococci occurs primarily by direct contact with infected secretions, either by inhalation of droplets or by hand or face contact. Because meningococci resist drying poorly, fomite spread probably does not often occur. Nasopharyngeal carriage rate is about $1 \%$ in young children ${ }^{71}$ and may be much higher during local outbreaks. The incubation period is from 2 to 10 days and is commonly 3 to 4 days. $^{32}$ In a large Belgian survey, ${ }^{52} 70 \%$ of cases of secondary meningococcal disease occurred within 7 days of the primary case and $83 \%$ occurred within 14 days. Communicability is presumably present until meningococci have been eliminated from the nasopharynx. Factors other than age that might influence susceptibility to invasive disease are largely unknown. The presence of group-specific anticapsular antibody is protective. Infants up to age 2 years are unable to produce antibody to many polysaccharide capsular antigens. Recently, asymptomatic congenital deficiencies of one of several complement components have been found in some persons who develop invasive meningococcal disease. ${ }^{60}$ The secondary attack rate in some settings has been high. In a 
Dade County, Florida, outbreak, there were three cases among 21 exposed children 4 years of age or less. ${ }^{103}$ In the Belgian study, ${ }^{52}$ secondary attack rates were 404/100,000 among daycare nurseries and 77/100,000 among older preschool children in an institutional setting (Table 4). The relative risk for children in the U.S. is assumed to be similar.

\section{MANAGEMENT}

Day-care centers must have a policy that assures that they are notified of all cases of meningococcal disease occurring in children or staff. Infections due to $N$. meningitidis must be reported to the local health department. Secondary cases of meningococcal infection may develop in day-care center staff and children who have been exposed to an index case. Therefore, close surveillance of all household and day-care center contacts must be maintained. Contact children or ädults in whom unexplained fever or rash develop must be examined immediately by a physician, and appropriate therapy with intravenous penicillin should be instituted. Throat or nasopharyngeal cultures for $N$. meningitidis are of no value. The extent of crowding at the day-care facility should be assessed, and efforts should be made to remedy the crowding without closing the center or dispersing the contacts to other day-care facilities. All household and day-care center contacts should be given antimicrobial prophylaxis without delay. Casual contacts and contacts of contacts need not be given prophylaxis. If the index organism is known to be sensitive to sulfonamide, the recommended regimen for prophylaxis is sulfadiazine, $10 \mathrm{mg} / \mathrm{kg}$ daily (maximum, $4 \mathrm{gm} /$ day) every 6 hours for 2 days. ${ }^{109}$ For sulfonamide-resistant organisms or when antibiotic susceptibility is not known, the preferred drug is rifampin, $20 \mathrm{mg} / \mathrm{kg}$ daily (maximum, $600 \mathrm{mg} /$ day) in two equal doses 12 hours apart for 2 days. Infants less than 1 month of age receive $10 \mathrm{mg} / \mathrm{kg}$ daily. A combination of minocycline and rifampin has been shown to be slightly more effective than rifampin

TABLE 4

Secondary Attack Rates Among Household, Day-care Nursery, and Preprimary School Contacts of Children With Meningococcal Disease*

\begin{tabular}{lrrrr}
\hline & $\begin{array}{c}\text { NO. } \\
\text { PRIMARY } \\
\text { CASES }\end{array}$ & $\begin{array}{c}\text { NO. } \\
\text { PERSONS } \\
\text { EXPOSED }\end{array}$ & $\begin{array}{c}\text { NO. } \\
\text { SECONDARY } \\
\text { CASES }\end{array}$ & $\begin{array}{c}\text { SECONDARY } \\
\text { ATTACK RATE } \\
\text { PER 100,000 }\end{array}$ \\
\hline Households & 1,665 & 5,112 & 35 & 685 \\
Day-Care nurseries & 28 & 991 & 4 & 404 \\
Preprimary schools & 227 & 18,160 & 14 & 77 \\
\hline
\end{tabular}

*Adapted from Dewals P, Hertoghe L, Borlée-Grimée I, et al ${ }^{36}$ Used by permission. 
alone, but unpleasant side effects occur in $33 \%$ of persons given the combined regimen. ${ }^{125}$ Rifampin is not currently available as a suspension for children, but such a suspension can be prepared by a pharmacist. The safety of rifampin in pregnant women has not been demonstrated. Rifampin may color urine or other body secretions red-orange and may permanently stain soft contact lenses. Because rifampin may interfere with the effectiveness of oral contraceptives, alternative contraceptive methods should be considered for the remainder of the menstrual cycle when rifampin is prescribed. Persons receiving prophylaxis may be incubating a coprimary case of invasive disease and should still be monitored for signs of illness. Those recovering from meningococcal disease should receive prophylaxis before returning to the daycare center.

In continuing outbreaks, consideration should be given to administering meningococcal polysaccharide vaccine to susceptible contacts once the serogroup of the index organism is known. Vaccines containing serogroup antigens A, C, Y, and W135 are available. Group $\mathrm{C}$ vaccine is poorly effective in children of less than 2 years. Group A vaccine is effective above the age of 3 months. ${ }^{144}$ Use of vaccine should generally be coordinated with the local health department.

Cases of meningococcal disease in day-care centers will continue to occur. Physicians who care for children should attempt to influence operators of day-care centers to avoid overcrowded conditions. Proper ventilation must be assured. Reasonable hygiene measures to control respiratory secretions are desirable. Elimination of the problem must await the development of new meningococcal vaccines that are more immunogenic in young children.

\section{MUMPS}

Mumps is an acute viral illness characterized in children by mild systemic symptoms and parotitis. Mild, often subclinical, meningoencephalitis frequently accompanies acute infection. Pancreatitis, orchitis, and inflammation of minor salivary glands may also occur. The disease is generally mild in young children; subclinical disease occurs in a substantial proportion. ${ }^{89}$ More serious illness is probable in older children and adolescents.

Mumps remains the most common cause of viral parotitis; however, laboratory confirmation must be sought in immunized persons.

Mumps immunization, given at the currently recommended age of 15 months, has significantly reduced the number of mumps epidemics. Day-care centers have not been sources of mumps outbreaks.

152 


\section{TRANSMISSION}

Mumps is spread by direct contact or droplet spread of saliva or infectious oral secretions. The disease is communicable for several days before the onset of parotid swelling and until the swelling subsides, generally 7 to 10 days. The incubation period ranges from 2 to 3 weeks.

Immunized children and adolescents should be protected from acquiring natural disease. Most adults born before 1957 also are immune. About half of young adults and adolescents without a history of disease or immunization are susceptible.

\section{MANAGEMENT}

Children with suspected mumps should be excluded for the duration of parotid swelling or other clinical manifestationsabout 9 days. Occurrence of a case provides an excellent opportunity for day-care centers to review their immunization records of attendees. Immunization should be considered for those 12 months of age or older and may also be considered for susceptible adult staff members (especially men). There is no evidence that postexposure immunization or immunoglobulin administration is protective. ${ }^{4}$

\section{PEDICULOSIS}

Pediculosis is an infestation of the scalp hairs by the louse Pediculus capitis. This insect is a gray, hemophagic ectoparasite, 2 to $3 \mathrm{~mm}$ long, whose natural ecosystem is limited to a space about $1 \mathrm{~cm}$ above the human scalp. Head lice do not parasitize and cannot be acquired from nonhuman hosts such as domestic animals. The life span of each insect is a maximum of 40 days. Survival away from the human host is limited to 3 to 10 days. ${ }^{107}$ The lice obtain nourishment by sucking capillary blood from the scalp. Female lice attach egg cases (nits) to the hair shafts at or very near the scalp. Proximity to the scalp is necessary because loose eggs optimally hatch at $34^{\circ} \mathrm{C}$ and rarely at temperatures below $22^{\circ} \mathrm{C}$. After 8 to 11 days of incubation, the egg cases release three louse nymphs, capable of independent life. The short life span of the louse is compensated for by its fecundity and short reproductive time.

The exact prevalence of head lice infestation in the U.S. is unknown, although current data ${ }^{119,136}$ suggest an increase during the past two decades. In grade schools, prevalence rates of $3 \%$ to $10 \%$ have been reported ${ }^{62}$ Many elementary schools in California now have active pediculosis identification and control programs. Outbreaks of pediculosis probably occur less frequently in preschool children ${ }^{134}$ but can be expected in any set- 
ting in which numbers of children are in close contact, such as a day-care center.

Clinical manifestations of head lice infestation include scalp pruritus, excoriations, secondary pyoderma, and regional lymphadenopathy. Physical evidence of pediculosis includes live lice and nits on hair shafts, which may require diligent search in mild infestations. In addition, louse detritus, such as moulted skins and small black concretions of fecal material and dried blood, may be found on the neck or collar of affected children.

\section{TRANSMISSION}

Pediculosis is transmitted by direct contact or fomite spread of live lice. The lice do not jump or fly. Nits are not shed from the hair shafts, and this is therefore not generally a mode of transmission. Fomites which may harbor live lice include hats, coats, combs, brushes, cots, and bedding. A major factor in the spread of head lice in the school setting has been common storage of hats and coats, ${ }^{134}$ which allows cross transfer of lice. Like many transmissible agents, lice flourish in conditions of overcrowding and poor hygiene. However, personal cleanliness or its lack is not the major determinant of the risk of pediculosis, as clean, well-dressed children "from good homes" can have lice.

\section{MANAGEMENT}

Day-care center personnel should be well informed about the signs and symptoms of pediculosis. Individual storage of hats, coats, and bedding materials should be provided. All children attending a facility should be periodically inspected for signs of pediculosis. Once an infestation is found, all index children must be removed from the center until treatment has begun. All other children must be examined by a knowledgeable person, such as a nurse or physician, to look for evidence of infestation. Adult staff should be examined also. Parents should be informed to look for signs of head lice appearing in subsequent days or weeks.

Nonspecific treatment measures are of little value. Ordinary shampooing does not kill or remove lice or nits. Cutting the child's hair short is of value only if the hair is maintained at less than one-third inch long. Such short hair is usually not cosmetically acceptable to children or parents. Nit removal alone is difficult as a control measure because: (1) live lice are not removed; (2) most "live" nits are found less than one-fourth inch from the scalp and therefore are hard to see and remove; and (3) nits found more than one-fourth inch from the scalp are already hatched, so that their removal is of no medical value. Nit removal is often undertaken for cosmetic reasons or to satisfy public health, school, or day-care facility requirements for proof of 
therapy. Combing out nits is best accomplished by using a metal or hard plastic comb with beveled teeth 0.1 to $0.3 \mathrm{~mm}$ apart. Combs of varied effectiveness are now found in boxes of overthe-counter pediculocides. To remove nits, the hair must be combed meticulously, clump by clump, while the hair is wet and lathered with ordinary shampoo. Detailed instructions are usually included with the comb when purchased.

Specific topical therapy with an effective pediculocide is obligatory for adequate treatment. Table 5 lists common agents generally considered safe and effective for head lice. Lindane (gamma isomer of benzene hexachloride) is the most commonly used prescription pediculocide in the U.S. It has been associated with seizures in infants treated all over the body for an extended time to control scabies. Such adverse effects have not been associated with the brief exposures used for treatment of head lice. ${ }^{123}$ Resistant lice have been documented in Europe and occasionally occur in this country. ${ }^{31}$ Malathion lotion is highly pediculocidal and moderately ovicidal. Adverse effects have been minimal. ${ }^{123,173}$ In one recent study, Taplin and co-workers ${ }^{173}$ found this agent to be $100 \%$ pediculocidal at 24 hours and $95 \%$ pediculocidal after 7 days, suggesting in vivo ovicidal or residual pediculocidal activity. In some cases of heavy infestation, a second treatment may be required because of the greater likelihood of survival of some eggs. Preparations containing pyrethrins and piperonyl butoxide are available over the counter. This combination of agents is the only effective over-the-counter pediculocide ${ }^{117,149}$ and is marketed under a number of brand names. Because pyrethrins are obtained from chrysanthemum, which is related to ragweed, patients with ragweed allergies should be cautioned about the use of these agents.

TABLE 5

Common Pediculocide Regimens

\begin{tabular}{|c|c|c|c|}
\hline AGENT & BRAND & AVAILABILITY & OVIDICAL? \\
\hline $\begin{array}{l}\text { Lindane (benzene } \\
\text { hexachloride) }\end{array}$ & Kwell shampoo & Prescription only & No \\
\hline Malathion & Prioderm lotion & Prescription only & Yes \\
\hline $\begin{array}{l}\text { Pyrethrins and } \\
\text { piperonyl butoxide }\end{array}$ & $\begin{array}{l}\text { RID, A-200, } \\
\text { Triple X, Barc, } \\
\text { and other } \\
\text { lotions or } \\
\text { shampoos }\end{array}$ & Over the counter & No \\
\hline Combs & Derbac and others & - & - \\
\hline
\end{tabular}

Kwell: Reed and Carnrick, Piscataway, New Jersey.

Prioderm: Purdue Frederick Co., Norwalk, Connecticut.

RID: Pfizer, Inc., New York, New York.

A-200: Norcliff-Thayer, Inc., Tuckahoe, New York.

Triple-X: Youngs Drug Products Corp., Piscataway, New Jersey.

Barc: Commerce Drug Co., Plainview, New York.

Derbac: Cereal Soaps Co., Div. Johanson Manufacturing Co., Boonton, New Jersey. 
Lice can survive on clothing or bed linen. Disinfection can be accomplished by washing at $>140^{\circ} \mathrm{F}$ for 20 minutes, by drycleaning, or by storage for 30 days.

During a day-care center outbreak, infested children must be removed from the facility until adequate treatment has been verified. Requiring complete nit removal before re-entry to the facility may prove difficult for some parents but appears to be a successful way of documenting that treatment has occurred. Except in severe or recurrent infestations, it would seem reasonable to allow the child back after initial pediculocide treatment and nit removal. When a nonovicidal agent has been used, parents should be reminded not to forget the second treatment at 7-10 days. Because pediculosis commonly affects more than one member of a family, all persons in the home should be examined by a skilled observer, and all infested persons must be treated. If reinfestation occurs within a household after adequate pediculocide therapy, all family members should be treated simultaneously, using a different pediculocide.

\section{PERTUSSIS}

Pertussis, or "whooping cough," is caused by Bordetella pertussis, a gram-negative rod that produces an infection resulting in inflammatory changes in the tracheobronchial tree. The disease is classically of long duration. The incubation period is 7-10 days, followed by 2 weeks of catarrhal stage with manifestations of runny nose and cough; this is followed by 2 weeks of paroxysmal stage manifested by paroxysms of coughing. In children beyond infancy, these paroxysms often end in a "whoop," which gives the disease its common name. In younger children, the paroxysms end in an apneic spell, which is the greatest risk factor in infants under 6 months. After the paroxysmal stage there is an additional 2 weeks or more of prolonged coughing. The disease is communicable to susceptible individuals and is apt to spread through families, institutions, or day-care centers. ${ }^{27}$ of susceptible persons, $90 \%$ are likely to be infected in a household setting. ${ }^{41}$ Adults are often not immune or are partially immune. ${ }^{29}$ Partial immunity may result in a modified course with chronic cough and bronchitis but without paroxysms.

The incidence of disease in the U.S. is low because of current widespread immunization with pertussis vaccine. ${ }^{26}$ However, when immunization has been discontinued in countries such as Japan and Great Britain, outbreaks of the disease have occurred. ${ }^{41,148,170}$ Mortality is limited mainly to the age group under 6 months. ${ }^{30}$ The many serious sequelae include pneumonia, neurologic manifestations (convulsions and encephalopathy), epistaxis, and subconjunctival hemorrhage. Pertussis is most communicable during the catarrhal stage, in which the spread is by respiratory droplet transmission. Without antimicrobial ther- 
apy, communicability lasts about 2 weeks. Therapy with erythromycin reduces this period to 4-7 days.

The diagnosis of pertussis is clinical. Laboratory confirmation is obtained by isolating Bordetella pertussis from a nasopharyngeal culture or by demonstrating the organism by immunofluorescence, a procedure that is not generally available.

The control of pertussis depends on immunization. ${ }^{7}$ Immunization is effective and is recommended for children from 2 months through 6 years of age. The vaccine available currently carries a significant rate of complications, the most common of which are fever and a sore arm. ${ }^{70}$ Beyond these minor events, complications include convulsions, which occur in approximately 1 in 2,000 immunizations. A more serious manifestation, such as encephalopathy, occurs in approximately 1 in every 300,000 cases. ${ }^{7{ }^{41}}$ Because of complications and adverse media publicity, the validity of pertussis immunization is being questioned at the present time. ${ }^{91}$ If this results in failure of immunization, pertussis may present a serious problem for day-care centers in the future.

The control of pertussis in day-care centers consists principally in encouraging all children who attend the center to be immunized. Each day-care center should have a policy in this respect, which may range from requiring pertussis immunization of each child before enrollment, to strongly recommending immunization, or to at least keeping a careful record of children who are and are not immunized, so that control measures can be taken if a case of pertussis appears.

Recommendations for Control of Pertussis in Day-Care Centers

1. The day-care center should require immunization of all children attending the center.

2. Immunization records should be reviewed annually to be sure that they are kept current.

3 . The day-care center should have a current list of all children who are not immunized because of religious or medical reasons.

4. The day-care center should be notified of all cases of pertussis among the children and staff. Suspected or atypical cases should also be reported. The local health department must also be notified of all cases of pertussis.

5 . Children with pertussis may return to the day-care center 3 weeks after onset of disease or 1 week after initiation of therapy with erythromycin.

6. Parents of children attending day-care centers need to be notified of exposure to pertussis, so that appropriate steps may be taken to protect their children.

7. Exposed children who are incompletely immunized and who 
have not had an injection within the last month should be given a DTP injection and the required number of additional injections to bring that immunization up to date. Additionally, these children should receive erythromycin $(50 \mathrm{mg} / \mathrm{kg} /$ day in three divided doses) for 10 days.

8. Persons over 7 years of age must not receive pertussis vaccine. Antimicrobial prophylaxis with erythromycin might be administered in case of very close contacts.

9. Both exposed children and staff members should be monitored for 14 days for the appearance of respiratory symptoms in order to diagnose and treat secondary cases of pertussis at the earliest opportunity.

\section{RESPIRATORY INFECTIONS}

Acute respiratory infections are the most common illnesses for which infants and children are brought in to physicians' offices for medical attention. These account for about $20 \%$ to $30 \%$ of all visits to pediatricians ${ }^{93}$ and carry a definable morbidity in childhood. $^{164}$

There are well over 100 microorganisms that cause acute respiratory illnesses, and a detailed discussion on the possible causes, epidemiology, pathogenesis, and clinical spectrum of these infections is beyond the scope of this section. The inter-

\section{TABLE 6.}

Common Respiratory Infections in Infants and Preschool Children

\begin{tabular}{|c|c|c|}
\hline CONDITION & COMMON INFECTIOUS AGENTS & LESS COMMON CAUSES \\
\hline Common cold & $\begin{array}{l}\text { Khinovirus, parainfluenza, } \\
\text { Respiratory syncytial } \\
\text { virus }\end{array}$ & $\begin{array}{l}\text { Adenovirus, enterovirus, } \\
\text { Influenza, Epstein- } \\
\text { Barr virus, } M \text {. } \\
\text { pneumoniae }\end{array}$ \\
\hline $\begin{array}{l}\text { Nasopharyngitis } \\
\text { and tonsillitis }\end{array}$ & $\begin{array}{l}\text { Adenovirus, enterovirus, } \\
\text { influenza, parainfluenza, } \\
\text { Epstein-Barr virus }\end{array}$ & $\begin{array}{l}\text { Rhinovirus, respiratory } \\
\text { syncytial virus, } \\
\text { bacteria, Herpesvirus } \\
\text { hominis }\end{array}$ \\
\hline Croup & Parainfluenza, influenza A & $\begin{array}{l}\text { Adenovirus, respiratory } \\
\text { syncytial virus }\end{array}$ \\
\hline Acute bronchitis & $\begin{array}{l}\text { Adenovirus, respiratory } \\
\text { syncytial virus, influenza }\end{array}$ & $\begin{array}{l}\text { Rhinovirus, enterovirus, } \\
M \text {. pneumoniae, } \\
\text { bacteria }\end{array}$ \\
\hline Bronchiolitis & $\begin{array}{l}\text { Respiratory syncytial virus, } \\
\text { parainfluenza }\end{array}$ & $\begin{array}{l}\text { Adenovirus, influenza, } \\
\text { rhinovirus }\end{array}$ \\
\hline Pneumonia & $\begin{array}{l}\text { Respiratory syncytial virus*, } \\
\text { Chlamydia trachomatist, } \\
\text { parainfluenza }\end{array}$ & $\begin{array}{l}\text { Influenza, adenovirus, } \\
\text { bacteria }\end{array}$ \\
\hline
\end{tabular}

$*<1$ yr old.

$\dagger<6$ mos. old. 
ested reader is referred to standard textbooks. ${ }^{63,109}$ However, a few points deserve emphasis: (1) The causes and incidence of common respiratory infectious syndromes are generally predictable (Table 6). Some infectious agents, such as influenza viruses A and B, occur in predictable epidemics. Others are invariably seasonal: respiratory syncytial virus from November to May; parainfluenza and rhinoviruses in the spring, early summer, and fall; adenoviruses throughout the year. (2) The clinical symptoms and severity of illness vary with the age of the infected host: respiratory syncytial virus frequently causes pneumonia, bronchiolitis, or apnea in the young infant but only mild upper respiratory symptoms in the older child or adult. Conversely, infections due to Epstein-Barr virus or Mycoplasma pneumoniae are usually asymptomatic or cause mild nasopharyngitis in the young child but are more severe in older populations. (3) Infection with these agents does not always confer protective immunity against reinfection or recurrence. The clinical expression of subsequent infections varies with specific agents and the host's response to them. ${ }^{51}$ Much remains to be learned about the pathogenesis of acute respiratory infections and about host immune response before effective modes of treatment and prevention can be implemented.

\section{EPIDEMIOLOGY}

In the setting of family life, the average number of "colds" per year in children is three to eight. ${ }^{63}$ It is well understood that school age children become infected and introduce secondary infections in the home. ${ }^{70,87}$ The present trend toward increased attendance at day-care centers and preschool programs would be expected to increase early primary infections in the younger children and make them the source of secondary infections in the family. Yet, very few studies have evaluated the impact of day-care center activities on transmission of respiratory illnesses and the health of children and their household contacts. Most studies in the U.S. have been conducted in day-care centers located on university campuses. These centers, such as the Frank Porter Graham Day-Care Center at the University of North Carolina, Chapel Hill, have a relatively closed and stable population of attendees. ${ }^{51,71}$ Although such studies give extremely valuable data on the pathogenesis and longitudinal morbidity of common childhood illnesses, the epidemiology of these infections may be different in other day-care centers having a more open enrollment or rapid turnover of attendees. No studies have been done to demonstrate definitively whether the risk of respiratory diseases is increased in children attending day-care centers compared with that in children cared for at home or in other settings. 


\section{Transmission}

Respiratory pathogens can be spread by aerosols, droplets, and direct contact with infected secretions. However, the role of fomites is also most important. Ill persons with a high concentration of virus in secretions exhibit a propensity to contaminate their hands and objects in the environment with virus. Rhinoviruses can be recovered from $40 \%$ to $90 \%$ of the hands of persons with colds and from $6 \%$ to $15 \%$ of diverse environmental objects such as doorknobs, dolls, coffee cups, and glasses. ${ }^{78} \mathrm{Rhi}-$ noviruses can survive in the environment for hours. Similarly, influenza viruses can survive for 24 to 48 hours on hard, nonporous surfaces (plastic, steel) and up to 8 to 12 hours on cloth, paper, and tissues. ${ }^{15}$ Respiratory syncytial virus in freshly obtained infant secretions can be recovered from various fomites from 30 minutes up to 6 hours. ${ }^{86}$ Viruses can be transferred to the hands by touching these contaminated surfaces. Finally, rubbing the eye or "picking" the nose, observed to be frequent, normal human behavior, allows self-inoculation.

The patterns of respiratory virus shedding in children have been well studied in hospitalized patients as well as in family settings and in some day-care centers. Table 7 briefly summarizes some common patterns and periods of communicability for specific agents. However, Strangert and colleagues ${ }^{167}$ observed in their study of day-care children in Sweden that when a virus was first isolated from the oropharynx, children were asymptomatic or had only rhinitis in $73 \%$ of cases. We do not know whether infected persons are most contagious in the prodrome phase of their illness or at the peak of clinical symptoms. The role of the asymptomatic carrier in transmitting disease is even

TABLE 7.

Patterns of Respiratory Virus Shedding in Children

\begin{tabular}{|c|c|c|c|}
\hline VIRUS & $\begin{array}{c}\text { PERIOD OF } \\
\text { PEAK SHEDDING }\end{array}$ & $\begin{array}{c}\text { POST-ONSET } \\
\text { DURATION OF } \\
\text { SHEDDING }\end{array}$ & $\begin{array}{c}\text { USUAL } \\
\text { PERIOD OF } \\
\text { COMMUNICABILITY } \\
\text { (DAYS) }\end{array}$ \\
\hline Influenza A & $\begin{array}{l}24 \mathrm{hr} \text { before and } \\
48 \mathrm{hr} \text { after } \\
\text { onset of } \\
\text { symptoms }\end{array}$ & $\leq 2 \mathrm{wks}$ & $3-7$ \\
\hline Parainfluenza & Day 2 of illness & $2-4$ wks & 7 \\
\hline $\begin{array}{l}\text { Respiratory syncytial } \\
\text { virus }\end{array}$ & $\begin{array}{l}\text { Days } 1-3 \text { of } \\
\text { illness }\end{array}$ & $1-21$ days & Unclear \\
\hline Rhinoviruses & $\begin{array}{l}\text { First few days } \\
\text { of illness }\end{array}$ & $\leq 3 \mathrm{wks}$ & Unclear \\
\hline Adenovirus & $\begin{array}{l}\text { First few days } \\
\text { of illness }\end{array}$ & $\begin{array}{l}\leq 3 \text { months } \\
\text { in stool }\end{array}$ & Unclear \\
\hline
\end{tabular}


less well known. However, the Swedish data might indicate that dismissing symptomatic children is of limited value in controlling the spread of infection.

\section{RECOMMENDATIONS FOR CONTROL OF RESPIRATORY INFECTIONS in Day-Care Centers}

It is beyond the scope of this review to discuss the symptomatic or specific therapy of each infectious agent that might be encountered in the day-care center. Although antiviral agents, such as amantadine, ribavirin, interferon, and other drugs are available either commercially or on an experimental basis, the lack of clinical studies precludes any specific recommendations on the use of these agents in the setting of day-care centers to prevent transmission of disease or to control outbreaks. Similarly, the prophylactic use of influenza vaccine has never been evaluated in the setting of day-care centers, although it has been quite successful in adult nursing homes.

Centers caring for infants and children should be encouraged to separate these children into cohorts and to maintain them in as stable a group as possible. Staff and children should be instructed about the importance of minimizing the spread of respiratory secretions by practicing good hygiene: careful disposal or cleaning of contaminated articles and surfaces and thorough handwashing, especially after blowing noses or handling articles contaminated with nasal or oral secretions. In hospital settings, infection control procedures such as emphasis on handwashing and cohorting of staff and infants have been successful. ${ }^{85}$ Disinfectants containing tincture of iodine and a phenol/alcohol mixture (Lysol)* may be more effective than others. Use of disposable handkerchiefs, perhaps impregnated with virucidal agents, is a potentially useful approach. ${ }^{48}$

Although febrile and ill children should be referred for medical evaluation or should temporarily not come to the day-care center until they are improved, it would be impractical to exclude all children with "a running nose or cough." A physician who sees a day-care center attendee with a specific infection of high morbidity and communicability should probably advise the director of the center. Increased awareness of the disease may lead to early diagnosis of secondary cases. Assistance from public health authorities can be sought in unusual outbreaks.

\section{RUBELLA}

Rubella is an acute viral exanthematous disease characterized by minimal systemic signs and lymphadenopathy, especially of the postauricular, occipital, and posterior cervical nodes. Al-

\footnotetext{
*Lysol: Sterling Drug Co., Montvale, New Jersey.
} 
though the disease is generally benign in children, infection during early pregnancy may result in severe birth defects, the so-called congenital rubella syndrome.

The diagnosis is easily missed because of the mildness of this illness and diversity of initial manifestations. The diagnosis of rubella must never be made in the nonepidemic setting without serologic confirmation. Conversely, the diagnosis should be entertained in unimmunized persons who show any acute nonspecific exanthematous illness without identifiable cause.

Rubella outbreaks have become exceedingly rare since the introduction of an effective, live attenuated viral vaccine. Sporadic cases of congenital rubella syndrome continue to be reported, also at a reduced rate. Postnatal rubella is uncommon in children less than 1 year of age. Current recommendations call for rubella immunization at $\mathbf{1 5}$ months of age. Rubella outbreaks in day-care centers have not been reported.

\section{Transmission}

Postnatal rubella is spread to close contacts by exposure to pharyngeal secretions. Virus may be isolated for 1 week before the onset of rash and may persist in the throat for 2 weeks after the onset of rash. The incubation period ranges from 14 to 21 days. Congenitally infected infants may excrete virus in urine and respiratory secretions and may remain infectious for weeks to several years after birth.

Susceptible persons in close contact with a case of rubella are likely to become infected. About $15 \%$ of unimmunized young adults and adolescents can be expected to be susceptible.

\section{MANAGEMENT}

Because of the mild nature of the illness in children, no special precautions are necessary for young contacts. There is no evidence that postexposure immunization or passive prophylaxis with immunoglobulin is helpful in preventing secondary cases. However, postexposure immunization of children is not contraindicated. Immunization records should be reviewed and immunization of susceptible children 12 months and older should be considered.

Parents and staff members should be advised early of potential exposure, so that pregnant and possibly pregnant women can consult their physicians regarding immune status. Immunization of women known or suspected to be pregnant is contraindicated. ${ }^{2}$

Prevention of future cases in day-care centers requires strict enforcement of immunization practices. In addition, physicians must make every effort to confirm suspected cases and to identify potential day-care center involvement. 


\section{SALMONELLA}

Salmonella gastrointestinal infection is a rare cause of epidemics of diarrhea in day-care centers. At least two such outbreaks, however, have been recognized recently. ${ }^{59,115}$ Moreover, data from outbreaks affecting households ${ }^{161,189}$ and institutions that care for children ${ }^{161}$ suggest that interperson spread by the fecal-oral route does occur within a defined living environment.

Bacteria of the genus Salmonella are ubiquitous and include over 2,200 known serotypes, such as Salmonella typhi and $S$. paratyphi in humans, $S$. choleraesuis in pigs, $S$. gallinarum in fowl, and $S$. dublin in cattle. These zoonotic reservoirs frequently provide the source for foodborne outbreaks, the most common source of Salmonella infection in humans. In the laboratory, Salmonella isolates are classified into serologic groups A, B, C1, C2, D, E, and I. Recent isolates associated with gastroenteritis in the U.S. have been distributed as follows: S. typhimurium (group B), 34\%; S. enteritidis (group D), 9\%; S. heidelberg (group B), 7\%; and S. newport (group C2), 6\%. ${ }^{38}$

Infections caused by Salmonella species in children include enteric fever (typhoid-like illness) and gastroenteritis. Bacteremia is common in enteric fever and may occur during the course of Salmonella gastroenteritis, especially in infants less than 1 year of age. Focal infections, such as meningitis and osteomyelitis, may occur as a consequence of bacteremia. Many cases of Salmonella bacteremia probably go unrecognized and are self-limited except in infants or compromised hosts, such as children with sickle cell disease. Asymptomatic stool excretion of Salmonella organisms after infection is common. Excretion frequently ceases after about 2 weeks but may last several months. ${ }^{132}$ Manifestations of enteric fever include fever, malaise, headache, abdominal tenderness, rash, and systemic toxicity. Gastroenteritis is usually manifested by abrupt onset of fever and diarrhea with abdominal cramps and with or without vomiting. Occasionally, signs of dysentery, including tenesmus and bloody stools, may be present. The diagnosis is established by stool culture (preferable to rectal swab) on selective media.

\section{TRANSMISSION}

In 1982 , Lieb and associates ${ }^{115}$ reported an outbreak of $S$. schwarzengrund gastroenteritis in a day-care center in Northwest Florida. The organism was recovered from the stools of 14 of 61 children attending the facility. The median age of infected children was 2 years. Nine of the culture-positive children had diarrhea or other gastrointestinal symptoms or signs. The periods of time between the onset of illness in the children (during a 24-day period) suggested interperson transmission. Foodborne transmission is generally associated with outbreaks of Salmonella gastroenteritis because a relatively large inoculum is re- 
quired to cause disease. Estimates have placed the inoculum size at about $10^{5}$ organisms. ${ }^{146}$ Recently, however, it has been suggested that less manifest infections may occur with smaller inocula, in the range of $10^{3}$ organisms. ${ }^{21}$ Fecal inocula can be found on the hands and environmental surfaces of day-care centers, ${ }^{58}$ presumably reflecting poor hygiene associated with the presence of small children. In addition, fecal-oral transmission may be facilitated in the day-care center setting because the relatively rapid stomach emptying of children compared with adults may contribute to gastric survival of Salmonella organisms. $^{21}$

The incubation period for Salmonella gastroenteritis is short, generally 12 to 36 hours. The period of communicability presumably persists throughout the period of fecal excretion. The concentration of organisms excreted by postinfection asymptomatic carriers may be low or may be as high as $10^{6}$ to $10^{9}$ organisms per gram of stool. ${ }^{158}$ Lack of contagiousness is generally demonstrated by two stool cultures negative for Salmonella, obtained at least 24 hours apart and at least 48 hours after any antimicrobial therapy. The secondary attack rate for Salmonella gastroenteritis in a defined living environment appears to be about $25 \%$ to $35 \%{ }^{59,157,189}$ Data are lacking about the relative risk for adult employees versus children in the day-care setting. In the outbreak reported by Lieb and associates ${ }^{115}$ one adult was asymptomatically infected.

\section{MANAGEMENT}

The day-care center should have a policy that assures that it will be notified of all cases of Salmonella infection that occur in children or adult staff of the facility. Salmonella infections must be reported to the local health department. Children with symptomatic Salmonella gastroenteritis should be excluded from the center until they become asymptomatic and diarrhea has ceased. Other children and staff should have stool cultures obtained to identify asymptomatic infections. When possible, asymptomatic children and staff with positive cultures should be placed in a separate cohort. Cohorting should continue until stool cultures become negative. Staff must use extra care in handwashing and disposal of potentially contaminated diapers. ${ }^{17}$ Environmental surfaces used for changing diapers must be cleaned frequently with suitable disinfectant. Toilet-trained children must not take part in food preparation until their stools are negative for Salmonella. Parents should be discouraged from transferring children to another day-care center during an outbreak, to prevent extension of the infection to other day-care centers. Similarly, new children should not be accepted into the center until the outbreak is over.

Generally, Salmonella gastroenteritis is self-limited and re- 
quires no specific antibiotic therapy. In fact, antibiotic therapy may increase the likelihood of subsequent relapse. ${ }^{128}$ Antimicrobial therapy, however, is appropriate in several settings including those of enteric fever, focal infection, severe dysentery, prolonged symptomatic diarrhea with weight loss, enteritis associated with sustained bacteremia, and disease occurring in infants below 2 months of age or in the immunocompromised host. Ampicillin, amoxicillin, chloramphenicol, and trimethoprim-sulfamethoxazole are generally effective, but in vitro susceptibility studies should be performed. Prophylactic treatment of contacts is not indicated.

\section{SCABIES}

Scabies is an infestation of the skin, resulting from infection by the parasitic female mite Sarcoptes scabiei, variant hominis. The adult female mite is round, translucent, gray, and about 0.4 $\mathrm{mm}$ long. The mite buries itself beneath the stratum corneum of the skin, living out its 30-day life by burrowing along, feeding on cellular fluid, and laying two to three large eggs per day. After hatching, larval and nymphal mites scatter to embed themselves into the skin at distant sites. Despite its small size, the mite can traverse the skin at a rate of 1 inch per minute. ${ }^{124}$

In the last two decades, the incidence of scabies worldwide has dramatically increased, ${ }^{137}$ for causes which are unclear. ${ }^{29} \mathrm{Al}$ though scabies is most widespread in the developing world, U.S. outbreaks occur in all socioeconomic groups. The exact prevalence of scabies in the U.S. is not known, but in a recent study, ${ }^{163}$ scabies was present in about $2 \%$ to $4 \%$ of patients seen by dermatologists.

Clinical manifestations of scabies relate to the immunologic reaction of the host to the mite antigens in the skin. In a person who has never before had scabies, pruritus and inflammation appear 3 to 6 weeks after onset of infestation. Pruritus is often severe, worse at night, and usually leads to excoriation, bleeding, and crusting. Visible skin lesions may include papules, vesicles, and nodules and may affect many body areas, especially the wrists, fingers, skin folds, periumbilical area, and genitalia. The face and head are generally spared, except in infants. ${ }^{96}$ Similarly, classic serpiginous burrows are frequently absent in infants and small children $;^{68}$ commonly, vesicles of the palms and soles are found in this age group. Scabies is an imitator of other dermatologic conditions and should always be considered as a possible cause of any unexplained pruritic eruption. Because it may be complicated by superinfection with Group A Streptococcus, Staphylococcus aureus, or both, scabies must be suspected as the underlying cause of recurrent pyoderma. The diagnosis of scabies is generally made by the presence of a characteristic pruritic rash and a positive epidemiologic history of exposure. 
Less typical cases may be confirmed by microscopic examination of skin scrapings. A thin layer of mineral oil is placed over an affected area, and the skin is scraped with the side of a scalpel blade. The material is placed on a glass slide and examined under low power. The presence of mites, eggs, or mite feces is diagnostic of scabies.

\section{TRANSMISSION}

Scabies is transmitted predominantly by direct contact with an infested person. During World War II, Mellanby ${ }^{124}$ demonstrated the relative difficulty of spreading mite infestation via fomites. Intrafamily spread, presumably from person to person, is most common with scabies. ${ }^{29}$ The role of fomites, such as clothes or bedding, in transmission among children or infants is unknown. In a British study, ${ }^{44}$ the secondary attack rate in the household setting was $38 \%$ for all household contacts and $49 \%$ for family contacts of preschool age. Transmission of scabies in the school setting apparently is infrequent, ${ }^{29}$ but preschool nursery outbreaks can occur. ${ }^{99}$ And, as with many other illnesses involving transmissible agents, overcrowded living environments are a significant factor in the spread of scabies. ${ }^{29}$

\section{MANAGEMENT}

Day-care center personnel must be aware of the signs and symptoms of scabies. Sharing of clothes, blankets, and bed linen among children at the facility should be discouraged. A child or staff member with an unexplained pruritic rash must be sent to a physician for diagnosis and management. All infested persons must be removed from the center until specific treatment has been instituted. Asymptomatic contacts should be observed closely for the development of clinical scabies as long as 4 to 6 weeks. If secondary cases are found, consideration should be given to treating all day-care center children and staff and all household members of each. In the setting of an outbreak, fomites such as bedding must be washed, dry-cleaned, or stored for over 1 week to eliminate any viable mites. Infested persons may return to the facility 24 hours after proper use of a scabicide. ${ }^{97}$

The treatment of individual cases of scabies necessitates proper use of an effective scabicide. Table 8 lists commonly used scabicides in the U.S. Patients must be carefully instructed in use of these agents. Lotion or cream must be evenly and completely applied to all skin areas from the neck down. Infants may need treatment of the face and head. Bathing before use may promote systemic absorption and is not currently recommended.

To successfully eradicate the parasite, all household members must be treated simultaneously, whether or not the signs or 
TABLE 8.

Scabicides Commonly Used in the U.S.

\begin{tabular}{|c|c|c|c|}
\hline AGENT & BRAND & $\begin{array}{l}\text { RECOMMENDED } \\
\text { APPLICATION }\end{array}$ & $\begin{array}{c}\text { SPECIAL } \\
\text { CONSIDERATION }\end{array}$ \\
\hline $\begin{array}{l}\text { Lindane (gamma } \\
\text { benzene } \\
\text { hexachloride) }\end{array}$ & $\begin{array}{l}\text { Kwell (lotion } \\
\text { or cream) }\end{array}$ & $\begin{array}{l}\text { Overnight, repeat } \\
\text { in } 5 \text { days }\end{array}$ & $\begin{array}{l}\text { CNS toxic; not for } \\
\text { use in infants, } \\
\text { small children, } \\
\text { or pregnant } \\
\text { women }\end{array}$ \\
\hline Crotamiton & $\begin{array}{l}\text { Eurax (lotion } \\
\text { or cream) }\end{array}$ & $\begin{array}{l}\text { Twice daily for } 3 \\
\text { days }\end{array}$ & $\begin{array}{l}\text { Topical antipruritic } \\
\text { effect }\end{array}$ \\
\hline $\begin{array}{l}\text { Sulfur }(6 \% \text { in } \\
\text { petrolatum) }\end{array}$ & - & $\begin{array}{l}\text { Nightly for } 3 \\
\text { nights }\end{array}$ & $\begin{array}{l}\text { Greasy, } \\
\text { malodorous, } \\
\text { stains clothes }\end{array}$ \\
\hline
\end{tabular}

Kwell: Reed \& Carnrick, Piscataway, New Jersey.

Eurax: Westwood Pharmaceuticals, Buffalo, New York.

symptoms of scabies are present. Patients should be told that, despite effective scabicide treatment, pruritus may persist for several weeks because of insect antigens remaining in the skin. Persistent itching is not an indicator of failure of therapy and does not warrant repeated or continuous use of the scabicide. Overtreatment should be discouraged by limiting the amount of cream or lotion prescribed to supply two courses of therapy; 30 $\mathrm{ml}$ of lotion is sufficient to cover the skin of an adult.

Lindane (gamma isomer of benzene hexachloride) is the most extensively used scabicide in the U.S. The cream or lotion is applied at night and rinsed off in the shower the next morning. Although a single application is usually successful, ${ }^{172}$ a second application in $\mathbf{5}$ days helps assure coverage of any missed skin areas and eradication of recently hatched larvae. Lindane is toxic to the central nervous system, ${ }^{111}$ and percutaneous absorption is increased in infants and small children. ${ }^{70}$ Current recommendations ${ }^{61,97,137}$ therefore suggest that lindane not be used to treat scabies in infants and small children or in pregnant women.

Crotamiton ( $10 \%$ cream or lotion) is an alternative agent that can be used in the treatment of scabies in infants, small children, and pregnant women. Crotamiton appears to have some topical antipruritic properties that may be helpful in the small patient. Serious toxicity of this agent has not been reported, but the absence of long-term side effects cannot be assumed. Treatment usually consists of two applications for 3 days.

Sulfur (6\%, precipitated, in petrolatum) has been in use for years as an effective, safe scabicide for use in infants. The preparation is used nightly for three consecutive nights. This agent is greasy and malodorous, and, because it stains clothing and sheets, may be poorly accepted by patients. 
In addition to specific scabicide therapy, an oral antipruritic, such as diphenhydramine or hydroxyzine, may be helpful. Topical steroids may be used after scabicide therapy to control localized itching, although these can potentiate and obscure untreated scabies. Persistent scabies nodules may occasionally require intralesional injection of corticosteroid to hasten resolution.

\section{SHIGELLA}

Outbreaks of gastrointestinal Shigella infections in day-care centers are common in the U.S. ${ }^{145,146,156,171,179,182}$ In fact, daycare center outbreaks of shigellosis have become a significant factor in the spread of this disease in the community. ${ }^{183}$ Because Shigella infection can be transferred by a very small bacterial inoculum, control of day-care center outbreaks is difficult and requires the attention and cooperation of day-care center operators, treating physicians, and local health authorities.

Shigella organisms are gram-negative aerobic bacilli that belong to the family Enterobacteriaceae. There are four relevant species: Shigella dysenteriae, S. flexneri, S. boydii, and S. sonnei. $S$. dysenteriae, which is associated with severe disease, is predominantly an organism of underdeveloped countries. Most U.S. cases of $S$. dysenteriae disease are directly imported. Recent U.S. isolates have been distributed as follows: $S$. sonnei, $69 \%$; $S$. flexneri, $27 \% ; S$. boydii, $2 \% ; S$. dysenteriae, $1 \%{ }^{156}$ Shigella is a pathogen of man only and has no other natural reservoir. Transmission of infection in developed countries usually occurs by interperson spread via the fecal-oral route. Foodborne and waterborne outbreaks occur with some frequency in underdeveloped countries.

In a typical case of shigellosis, the patient has sudden onset of fever and profuse, watery diarrhea. Cramping abdominal pain, the appearance of blood and mucus in the stool, and tenesmus soon supervene. Symptoms generally last 3 to 5 days but on occasion may persist for 2 weeks. In children, the infection is commonly associated with systemic toxicity and with leukocytosis in which large numbers of immature neutrophils appear in the peripheral circulation. Less severe clinical infections, such as mild, watery diarrhea, occur on occasion, especially from infection with S. sonnei. Asymptomatic intestinal infections may occur, but long-term carriers are rare. Complications of shigellosis include dehydration and electrolyte imbalance, arthritis and keratitis (Reiter's-like syndrome), and hemolytic-uremic syndrome (associated with $S$. dysenteriae, type I). Acute febrile convulsions may develop early in shigellosis in children and can include direct CNS toxicity due to circulating Shigella neurotoxins. Shigellemia is rare but has been documented. ${ }^{119}$ On occasion, shigellosis may be accompanied by bacteremia involving other intestinal organisms. ${ }^{87}$ 
Outbreaks of shigellosis in day-care centers have increased during the last two decades as the number of centers has increased. ${ }^{182}$ The exact incidence is unknown, but Pickering and co-workers ${ }^{145}$ identified five Shigella outbreaks in 20 day-care centers studied prospectively in a 19 -month period. The rapid dissemination of disease during such episodes was well illustrated during a recent outbreak in a day-care center in California. ${ }^{179}$ The index case was a 15-month-old child with Shigella dysentery who was neither treated nor removed from the daycare center. Within 4 weeks, the infection had affected seven of 10 other infants at the facility and 14 of 25 parents and siblings of the infants, none of whom had direct contact with the facility. The extent of this epidemic appeared to result directly from failure of the treating physician and the operator of the day-care center to use proper measures to control the outbreak.

\section{TRANSMISSION}

Transmission of shigellosis from one person to another by the fecal-oral route is facilitated by the low inoculum $\left(10^{1}\right.$ to $10^{2}$ organisms) capable of causing disease. Presumably, both the hands of children and adult staff and environmental surfaces can harbor such inocula. ${ }^{59}$ Illness can be transmitted by asymptomatic as well as symptomatic persons. Infectivity continues until the organism is gone from the stools. The incubation period is 1 to 7 days and is commonly 2 to 3 days. The diagnosis may be suspected by the finding of blood and leukocytes in the stool and may be confirmed by stool or rectal swab culture. Excretion of Shigella organisms commonly ceases after 2 to 3 weeks but on occasion may last several months in the untreated person. Secondary attack rates in the setting of a day-care facility have ranged from $50 \%$ to $80 \%$ for children ${ }^{145,179,182}$ and $25 \%$ to $35 \%$ for adult staff. ${ }^{182}$ Of even greater significance as a public health problem is the spread of infection to family members beyond the facility. The risk of transmission of shigellosis to family members during an outbreak is $26 \%$ to $36 \%{ }^{145,183}$ for each person at risk. Risk appears to be age-related, and the highest attack rates occur among young siblings of index cases. In at least two extended urban outbreaks of Shigella dysentery, secondary spread of disease from day-care facilities seems to have been a principal mode of dissemination in the community. ${ }^{183}$

\section{MANAGEMENT}

The day-care center should have a policy that assures that it will be notified of cases of Shigella infection among children and staff. Shigella infections must be reported to the local health department. Children symptomatic with Shigella infection must be excluded from the center until they are asymptomatic and 
receiving treatment and diarrhea has ceased, and stool cultures must be performed on all day-care center children and staff. Those with positive cultures must be referred to a physician for treatment and must be excluded from the center unless strict separation into cohorts of infected and uninfected children and staff is possible. Such cohorting must provide separate toilet facilities. Asymptomatic persons, whether receiving antibiotic therapy or not, should be considered infectious until the results of stool cultures are known. Cohorting must be continued until all stool cultures are negative for Shigella. Two separate stool specimens are needed and must be obtained at least 24 hours apart and at least 48 hours after antibiotic treatment. Exposed children should be considered infectious until the results of stool cultures are known. Again, cohorting must be continued until all stool cultures are negative for Shigella, and two separate stool specimens must be obtained at least 24 hours apart and at least 48 hours after antibiotic treatment. Exposed children should not be allowed to transfer to another day-care center until the outbreak is over. Similarly, new children must not be accepted until all stool cultures are negative for Shigella. During the outbreak, the staff should be instructed in careful handwashing techniques. ${ }^{17}$ Areas used for changing diapers must be disinfected after each use. Young children should be supervised at toilet to ensure proper hygiene and handwashing. Food preparation within the facility should be discouraged for the duration of the outbreak, and, if possible, food should be prepared elsewhere.

The choice of antibiotic treatment for persons with positive cultures should reflect the sensitivity patterns prevalent in the community. Ampicillin and trimethoprim-sulfamethoxazole are commonly used in children and adults. Data ${ }^{55}$ from the San Francisco area reflect the emergence of antibiotic resistance among Shigella isolates. In that study, ${ }^{55}$ four of every five isolates were resistant to tetracycline, and more than one of five isolates were resistant to ampicillin. Resistance to trimethoprim-sulfamethoxazole is uncommon so far, and this combination drug is preferred in areas where ampicillin resistance is present or where local susceptibility patterns are not known. ${ }^{133}$ Amoxicillin is ineffective in shigellosis and should not be used. The use of antimotility agents such as diphenoxylate or paregoric may increase the severity of Shigella dysentery by preventing evacuation of bacterial toxins. ${ }^{56}$ These agents should be avoided. Prophylactic treatment of culture-negative contacts is not indicated.

Preventing the spread of shigellosis within and beyond daycare facilities is a significant public health concern. Each physician should be ready to work with patients, day-care center operators, and local health officials where such outbreaks occur in order to minimize the effect of this infection on the community. 


\section{GROUP A STREPTOCOCCUS}

Group A Streptococcus causes pharyngitis and skin infections in young children. Untreated infections may spontaneously resolve or may occasionally result in suppurative sequelae, including peritonsillar abscess, cervical adenitis, erysipelas, and septicemia. Infection with certain strains of group A Streptococcus may be followed by nonsuppurative, immunologically mediated sequelae, by acute glomerulonephritis, and by acute rheumatic fever (after pharyngitis). Classic streptococcal pharyngitis is unusual below the age of 3 years, but purulent upper respiratory mucositis may occur in this age group. Streptococcal skin infections, including impetigo, may occur at any age, including infancy. ${ }^{131}$ The incidence of outbreaks of streptococcal disease in day-care centers is unknown. The risk of spread of group A Streptococcus in other closed environments, such as family groups, is well recognized. ${ }^{25,113}$

\section{TRANSMISSION}

Rarely, outbreaks of streptococcal pharyngitis may be traced to food contaminated by organisms introduced during preparation. Generally, streptococcal infection is transmitted by direct contact with infected respiratory secretions or skin lesions. The role of fomites is unclear; however, sharing of food items, eating utensils, and towels may contribute to dissemination of the organism. The incubation period is 2 to 5 days for streptococcal pharyngitis and varies for impetigo, depending upon the presence of skin trauma, such as insect bites and scratches. Communicability for pharyngitis is maximal during the acute illness and decreases throughout several weeks in the untreated person. Untreated impetigo is contagious until all lesions are healed. The role of the carrier state in spreading the illness is unclear. Persons with a few organisms in respiratory secretions and no clinical disease do not appear to transmit infection. ${ }^{104}$ The secondary attack rate varies and is highest in settings of overcrowding or poor individual hygiene. Adults and children alike are at risk for group A streptococcal disease, although adults develop the infection less often.

\section{Management}

Day-care centers must have a policy assuring that they are notified of all cases of group A streptococcal disease that occur among its children or staff. Infections due to this agent should be reported to the local health department. Persons with active infection must be excluded from the day-care facility and referred to a physician for diagnosis, culture, and treatment. Exclusion should continue until 48 hours after specific antibiotic 
therapy has begun. Specific treatment of streptococcal pharyngitis shortens both the duration of clinical illness ${ }^{84,130}$ and the period of communicability. Treatment of impetigo similarly eradicates skin lesions and contagiousness. Penicillin is the most effective antibiotic for group A streptococcal infections. Recommended preparations and doses include benzathine penicillin G $(600,000$ units for children weighing $<60$ lb or $1,200,000$ units for those $\geq 60 \mathrm{lb}$, intramuscularly) or penicillin $\mathrm{G}$ or $\mathrm{V}$ (1 gm daily for 10 days in 3 or 4 doses). Persons allergic to penicillin may be treated for 10 days with erythromycin, clindamycin, or cephalosporin. Recently, resistance of up to 5\% of group A streptococcal isolates to erythromycin has been reported. ${ }^{80} \mathrm{Im}$ petigo caused by a combination of group A Streptococcus and Staphylococcus aureus may necessitate adding a semisynthetic penicillin or other therapy directed against penicillin-resistant staphylococci.

Symptomatic contacts must be referred for culture and treatment and must be excluded from the facility. Culture or chemoprophylaxis of asymptomatic contacts is generally not indicated. Strict hygiene must be observed, including frequent handwashing by the staff and careful separation of towels and eating utensils to prevent the spread of organisms. Sharing of food items such as popsicles and soda bottles should be discouraged. Personnel should be alert for signs and symptoms of streptococcal disease for several weeks after the treatment of initial cases.

\section{TUBERCULOSIS}

Tuberculosis is a granulomatous disease transmitted by $M y$ cobacterium tuberculosis. The disease has always been and still is a leading cause of morbidity and death throughout the world. The incidence among children in the U.S. whose parents were born here is low-estimated to be 1 to 2 per 10,000 children per year. ${ }^{39,151}$ However, the disease is much more common among new immigrants from war-torn and poverty-stricken countries, particularly those from Southeast Asia and Central America. ${ }^{73,150}$ Children under 3 years of age are especially susceptible to infection and are also prone to the development of serious extrapulmonary disease, such as tuberculous meningitis, as well as lymph node and bone disease. The disease is transmitted by droplet infection, usually from an adult with sputum positive for $M$. tuberculosis. Infection in children is usually not communicable. The initial pulmonary disease is a primary complex that does not communicate with the tracheobronchial tree. Children usually do not cough and do not bring up sputum.

The key to both diagnosis and control of tuberculosis in childhood is the tuberculin test. ${ }^{1}$ The standard intradermal (Man- 
toux) test using 5 T.U. of purified protein derivative is the most reliable form of testing. A multiple puncture test using prongs coated with either purified protein derivative or old tuberculin may be used as a screening test; it is cheaper and easier to administer but not as reliable. Immunologically competent children become tuberculin-positive 6 to 12 weeks after exposure and infection.

Thus, any exposed child should be tested immediately and, if negative, retested in 6 to 12 weeks. If the tuberculin test is positive, a chest film is performed as well as a clinical examination. Persons with positive results of a tuberculin test and no evidence of disease are known as reactors. Those whose tuberculin test has become positive within the preceding year are known as convertors. The latter are at greater risk of clinical disease developing.

Finding a young child who is a convertor should trigger an epidemiologic investigation for the infectious contact. The younger the child, the more likely it is that the contact is a household member. A contact could also be a staff person in a day-care center. ${ }^{106}$ Thus, periodic tuberculin testing of children provides clues to locating infectious adults as well as providing an opportunity to treat the child prophylactically with isoniazid (INH). A tuberculin test at the time of entry into day care is recommended for all children. Similarly, all adult caretakers should be screened for tuberculosis (tuberculin test and, if positive, chest film). The frequency of repeating tuberculin tests in day-care centers depends on local circumstances. In settings where the community has an appreciable incidence of tuberculosis or where many immigrants continue to arrive into the community, an annual tuberculin test is recommended. The interval may be increased to every few years where these factors do not exist.

Another important modality in controlling tuberculosis in children is prophylactic therapy with INH. ${ }^{9}$ Ample evidence exists that future clinical disease can be prevented by giving convertors and reactors INH for 1 year $(10 \mathrm{mg} / \mathrm{kg}$ per day once daily up to $300 \mathrm{mg}$ per day maximal dose). ${ }^{9}$, 94 This approach has been particularly effective in preventing extrapulmonary disease, such as tuberculosis meningitis. In children, the toxicity of INH is negligible; unfortunately, older persons have more frequently occurring toxic manifestations, principally hepatic disease, and INH prophylaxis is not recommended after the age of 35 years. ${ }^{9}$ Another obstacle to the success of this approach has been the development of INH resistance. Low in the U.S., the incidence of $\mathrm{INH}$ resistance has been as high as $25 \%$ in tubercle bacilli recovered from some population groups, such as Southeast Asian refugees. ${ }^{73,150} \mathrm{INH}$ prophylaxis is of no value against resistant organisms. 
ReCOMmendations For Control of Tuberculosis IN DAYCare Centers

1. Children enrolling in a day-care center should have a tuberculin test. The frequency of repeating this test depends on the local prevalence of tuberculosis. Advice may be sought from the local public health department. In high-risk settings, the tuberculin test should be repeated annually; in areas of lower risk, the test should be repeated at least every 2 years.

2. Day-care center staff should be screened for tuberculosis before employment. A tuberculin test, properly read and recorded, will suffice if it is negative. Persons who have positive test results should have a chest film performed.

3 . The day-care center must be notified of all cases of tuberculosis in children and staff. Reports must also be made to the health department, which usually assumes the responsibility for an epidemiologic investigation.

4. Children with positive tuberculin tests and negative chest films do not have communicable infection and may be enrolled without restrictions.

5. Children with primary tuberculosis usually do not have communicable infection and may be allowed to attend the daycare center. A medical opinion should be obtained about each case. Day-care center staff may be able to help with administering medications.

6. Day-care center staff who develop tuberculosis must be excluded from attendance until they are receiving adequate treatment and a valid medical opinion is obtained that they no longer have a communicable stage of disease.

7. Children known to be convertors or reactors should be encouraged to receive 1 year of prophylactic INH treatment.

8. Children exposed to tuberculosis while in day care should receive a tuberculin test and be retested in 2 months. If the initial test results are negative in children less than 6 years of age, they should also receive prophylactic INH during this 2-month period.

\section{VARICELLA}

Varicella, or chickenpox, remains the last of the major exanthematous diseases of childhood that causes a clinically apparent infection in almost all children.

The disease is caused by a DNA virus, a member of the herpesvirus group. The virus that causes varicella is the same one that produces herpes zoster, or shingles. Like other herpesviruses, the varicella zoster virus becomes latent after the initial infection; reactivation at a later time results in clinical herpes zoster, which can occur many times and affects principally older adults, although it may occur in childhood. ${ }^{184}$ 
The virus is transmitted by respiratory droplets. ${ }^{77}$ After a brief viremic phase, the virus seeds the reticuloendothelial cells, where it replicates during the incubation period, culminating in a second episode of viremia. This time, the virus seeds the skin and mucous membranes, resulting in clinical varicella. The incubation period is 14 to 21 days with a mean of 17 days. The disease starts with a maculopapular eruption that quickly becomes vesicular, then pustular, and is followed by crusting of the lesions. Thus, after the first 12 to 24 hours of illness, skin lesions of all stages are noted. The skin lesions are often found on the scalp as well as on all parts of the skin and mucous membranes. New lesions continue to break out for about 6 days; during this time, the child is mildly febrile. The child has communicable infection for 1 or 2 days before the first lesion is noted and until all the skin lesions crust. The clinical diagnosis is easily made, but, in case of doubt, presence of virus can readily be demonstrated by examining scraped vesicles with an immunofluorescent stain. ${ }^{184}$

The most common complication of varicella is pyogenic skin infection caused by scratching, which infects the vesicles with streptococci or staphylococci. Mild encephalitis and Reye's syndrome are uncommon complications. An important problem is visceral dissemination, including pneumonia, hepatitis, and encephalitis, which occurs in immunocompromised persons, particularly those being treated with powerful immunosuppressive drugs such as high-dosage glucocorticoids. ${ }^{152}$

In the U.S. and other developed countries, varicella is universal and occurs during childhood, so that $82 \%$ of children are seropositive by the age of 10 years.

Aiding our ability to manage exposure in hospitals and daycare centers, several modern tests for humoral immunity-the fluorescent antibody-membrane antigen test (FAMA); enzymelinked immunosorbent assay (ELISA); and the radioimmunoassay (RIA)-allow rapid, accurate, and inexpensive determination of susceptibility.

Protection of exposed susceptible children is possible through the administration of varicella zoster immune globulin, ${ }^{11,24,45}$ which must be administered within 72 hours of exposure in order to provide protection. Thus, prompt notification of the families of immunocompromised children that clinically significant exposure to varicella has occurred is important.

A live, attenuated varicella vaccine has been developed and is undergoing final clinical trials. In the near future, immunocompromised persons may thus be protected by active immunization. ${ }^{11,67}, 122$ 
RECOMMENDATIONS FOR CONTROL OF VARICELLA IN DAY-CARE CENTERS

1. Children with varicella must be excluded from school for 7 days after onset of the rash. It is not necessary that all crusts be off before being permitted to return.

2. Parents should be notified about the occurrence of varicella in the day-care center. Normal (not immunocompromised) children do not require any preventive measures. Most secondary cases occur 14 to 21 days later.

3. Children who are immunocompromised are at particularly high risk when exposed to chickenpox. The status of these children must be made known to the day-care center operators, so that their families might receive highest priority and urgency when notification of varicella exposure is necessary.

4. Most adults are immune to chickenpox; however, there is always concern among exposed day-care center personnel about acquiring chickenpox. Information about past history of chickenpox can be entered in personnel records. The few persons who do not remember having chickenpox might wish to have their immune status determined by laboratory means.

5. Adult caretakers with varicella or herpes zoster must be excluded from working at the day-care center during their infection.

Few adults in our country are seronegative. Recent studies have shown that very few expectant mothers (about 5\%) in the U.S. are susceptible and that less than $2 \%$ of reported cases in the U.S. occur in patients over 20 years old. However, in tropical and semitropical countries, from $25 \%$ to $40 \%$ of chickenpox cases occur in adults. This fact is particularly important for day-care centers because many of the staff might be recent immigrants, and the generalization that all adults have had chickenpox might not apply.

Relatively intimate contact is required for transmission. Attack rates for susceptible siblings in the home range from $60 \%$ to $90 \%$. Attack rates in school classrooms are much lower, but it is usually not clear if the exposed children in the classroom were susceptible.

After a period of latency and containment of the varicella, the herpesvirus may reappear as herpes zoster. ${ }^{184}$ Migration of the virus along the nerve is often accompanied by neuralgia; the lesions are typically confined to a dermatome and are maculopapular and vesicular. Herpes zoster is infectious; exposure to a patient with herpes zoster results in chickenpox in a susceptible person. Like chickenpox, herpes zoster may result in visceral spread in persons with compromised immunity; patients with Hodgkin's disease are particularly susceptible, both to having clinical zoster and to its visceral spread.

Because chickenpox is a benign disease in normal children and the public as well as medical view has been that every child 
eventually ...s chickenpox, there has never been much concern about exposure in the classroom or the day-care center. In contrast, chickenpox outbreaks on children's hospital wards have always been of great concern. ${ }^{98}$

However, with improved techniques of cancer chemotherapy and greater survival of adults and children, clinically significant numbers of immunocompromised children as well as adult staff members may be found in day-care centers. It is for this population that chickenpox is a threat.

Varicella has also been found to produce a congenital varicella syndrome $c_{m i}$ ing the first 6 months of pregnancy. ${ }^{28,} 185$ This syndrome is rare, probably because there are so few susceptible pregnant women. Thus, pregnant women working in day-care centers may also be at risk if they have not previously been infected.

\section{REFERENCES}

1. Ad Hoc Committee of the Scientific Assembly on Microbiology, Tuberculosis and Pulmonary Infections: American Thoracic Society: Control of tuberculosis. Am Rev Respir Dis 1983; 128:336-342.

2. Advisory Committee on Immunization Practices: Rubella prevention. MMWR 1981; 30:37-47.

3. Advisory Committee on Immunization Practices: Measles prevention. MMWR 1982; 31:217-224, 229-231.

4. Advisory Committee on Immunization Practices: Mumps vaccine. $M M W R$ $1982 ; 31: 617-625$.

5. Advisory Committee on Immunization Practices: Polysaccharide Vaccine for Prevention of Haemophilus influenzae Type b Disease. MMWR 1985; 34:201-205.

6. Advisory Committee on Immunization Practices: Recommendations for protection against viral hepatitis. MMWR 1985; 34:313-335.

7. Advisory Committee on Immunization Practices: Diphtheria, tetanus, and pertussis: Guidelines for vaccine prophylaxis and other preventive measures. MMWR 1985; 34:405-414, 419-426.

8. Ahlfors K, Ivarsson S-A, Johnsson T, et al: Risk of cytomegalovirus infection in nurses and congenital infection in their offspring. Acta Paediatr Scand 1981; 70:819-823.

9. American Thoracic Society and Centers for Disease Control: Treatment of tuberculosis. Am Rev Respir Dis 1983; 127:790-796.

10. Anders BJ, Lauer BA, Paisley JW, et al: Double-blind placebn controlled trial of erythromycin for treatment of Campylobacter enteritis. Lancet 1982; 1:131-132.

11. Baba K, Yabuuchi H, Takahashi M, et al: Seroepidemiologic behavior of varicella zoster virus infection in a semiclosed community after introduction of VZV vaccine. $J$ Pediatr 1984; 105:712-716.

12. Band JD, Chamberland ME, Platt T, et al: Trends in meningococcal disease in the United States, 1975-1980. J Infect Dis 1983; 148:754-758.

13. Band JD, Fraser DW, Ajello G: Hemophilus Influenzae Disease Study Group: Prevention of Hemophilus influenzae type b disease. JAMA 1984; 251:2381-2386.

14. Barenkamp SJ, Granoff DM, Munson RS Jr: Outer-membrane protein subtypes of Haemophilus influenzae type $\mathrm{b}$ and spread of disease in day-care centers. J Infect Dis 1981; 144:210-217.

15. Bean B, Moore BM, Sterner B, et al: Survival of influenza viruses on environmental surfaces. $J$ Infect Dis 1982; 146:47-51.

16. Bishop RF, Davidson GP, Holmes IH, et al: Virus particles in epithelial 
cells of duodenal mucosa from children with acute non-bacterial gastroenteritis. Lancet 1973; 2:1281-1283.

17. Black RE, Dykes AC, Anderson KE, et al: Handwashing to prevent diarrhea in day-care centers. Am J Epidemiol 1981; 113:445-451.

18. Black RE, Dykes AC, Sinclair SP, et al: Giardiasis in day-care centers: Evidence of person-to-person transmission. Pediatrics 1977; 60:486-491.

19. Blaser MJ, Feldman RA, Wells JG: Epidemiology of endemic and epidemic Campylobacter infections in the United States, in Newell DG (ed): Campylobacter: Epidemiology, Pathogenesis and Biochemistry, Proceedings of an International Workshop in Campylobacter Infection, University of Reading, March 24-26, 1981. Lancaster, Penn, MTP Press, 1982, pp 3-4.

20. Blaser MJ, LaForce FM, Wilson NA, et al: Reservoirs for human campylobacteriosis. J Infect Dis 1980; 141:665-669.

21. Blaser MJ, Newman LS: A review of human Salmonellosis: I. Infective dose. Rev Infect Dis 1982; 4:1096-1106.

22. Blaser MJ, Reller LB: Campylobacter enteritis. N Engl.J Med 1981; 305:1444-1452.

23. Blaser MJ, Waldman RJ, Barrett 'T, et al: Outbreaks of Campylobacter enteritis in two extended families: Evidence for person-to-person transmission. J Pediatr 1981; 98:254-257.

24. Brawley RL, Wenzel RP: An algorithm for chickenpox exposure. Pediatr Infect Dis 1984; 3:502-504.

25. Breese BB, Disney FA: Factors influencing the spread of beta hemolytic streptococcal infections within the family group. Pediatrics $1956 ; 17: 834$ 838.

26. Broome CV, Fraser DW: Pertussis in the United States, 1979: A look at vaccine efficacy. $J$ Infect Dis $1981 ; 144: 187-190$.

27. Broome CV, Preblud SR, Bruner B, et al: Epidemiology of pertussis, Atlanta, 1977. J Pediatr 1981; 98:362-367.

28. Brunell PA: Fetal and neonatal varicella-zoster infections. Semin Perinatol $1983 ; 7: 47-56$.

29. Burkhart CG: Scabies: An epidemiologic reassessment. Ann Intern Med $1983 ; 98: 498-503$.

30. Cadranel S, Rodesch P, Butzler J-P, et al: Enteritis due to "related Vibrio" in children. Am J Dis Child 1973; 126:152-155.

31. California State Department of Health Services: Head lice infestations: Difficulties in control. Calif Morb 1980; 5:1.

32. California State Department of Health Services: Control of Communicable Diseases in California. Sacramento, California, California State Department of Health Services, 1983.

33. CDC: Measles in military dependents-Texas. MMWR 1979; 28:58-60.

34. CDC: Campylobacter enteritis in a household-Colorado. MMWR 1979; 28:273-274.

35. CDC: Summertime measles-Georgia. MMWR 1979; 28:425-427.

36. CDC: Military to civilian transmission of measles-Illinois, Nebraska. $M M W R$ 1980; 29:13-15.

37. CDC: Measles in a day-care center-Washington. MMWR 1980; 29:426427.

38. CDC: Human Salmonella isolates-United States, 1982. MMWR 1983; $32: 598-600$.

39. CDC: Measles-United States, 1983. MMWR 1984; 33:105-112.

40. CDC: Tuberculosis-United States, 1984. MMWR 1985; 34:86-87.

41. Cherry JD: The epidemiology of pertussis and pertussis immunization in the United Kingdom and the United States: A comparative study. Curr Prob Pediatr 1984; 14(2):1-78.

42. The Child Day Care Infectious Disease Study Group: Considerations of infectious diseases in day care centers. Pediatr Infect Dis 1985; 4:124-136.

43. The Child Day Care Infectious Disease Study Group: Public health considerations of infectious diseases in child day care centers. J Pediatr 1984; 105:683-701. 
44. Church RE, Knowelden J: Scabies in Sheffield: A family infestation. $\mathrm{Br}$ Med $J 1978 ; 1: 761-763$.

45. Committee on Infectious Diseases, American Academy of Pediatrics: Expanded guidelines for use of varicella-zoster immune globulin. Pediatrics 1983; 72:886-889.

46. Committee on Infectious Diseases, Americun Academy of Pediatrics: Revision of recommendation for use of rifampin prophylaxis of contacts of patients with Haemophilus influenzae infection. Pediatrics 1984; 74:301-302.

47. Committee on Infectious Diseases, American Academy of Pediatrics: $\mathrm{He}$ mophilus type v polysaccharide vaccine. Pediatrics $1985 ; 76: 322-324$.

48. Couch RB: The common cold: Control? I Infect Dis 1984; 150:167-173.

49. Daum RS, Glode MP, Goldmann DA, et al: Rifampin chemoprophylaxis for household contacts of patients with invasive infections due to Haemophilus influenzae type b. J Pediatr 1981; 98:485-491.

50. Daum RS, Halsey NS: Counterpoint: The Red Book opts for red urine. Pediatr Infect Dis 1982; 1:378-381.

51. Denny FW, Clyde WA Jr, Collier AM, et al: The longitudinal approach to the pathogenesis of respiratory disease. Rev Infect Dis 1979; 1:1007-1015.

52. DeWals P, Hertoghe L, Borlée-Grimée I, et al: Meningococcal disease in Belgium: Secondary attack rate among household, day-care nursery and pre-elementary school contacts. $J$ Infect 1981; 3(suppl 1):53-61.

53. Dienstag JL, Szmuness W, Stevens CE, et al: Hepatitis A virus infection: New insights from seroepidemiologic studies. J Infect Dis 1978; 137:328340 .

54. Drake AA, Gilchrist MJR, Washington JA II, et al: Diarrhea due to Campylobacter fetus subspecies jejuni: A clinical review of 63 cases. Mayo Clin Proc 1981; 56:414-423.

55. Dritz S: Antibiotic susceptibility of shigellae in the San Francisco area. Calif Morb 1979; 41:1.

56. DuPont HL, Hornick RB: Adverse effect of Lomotil therapy in shigellosis. JAMA 1973; 226:1525-1528.

57. Dworsky ME, Welch K, Cassady G, et al: Occupational risk for primary cytomegalovirus infection among pediatric health-care workers. $N E n g l J$ Med 1983; 309:950-953.

58. Dworsky M, Yow M, Stagno S, et al: Cytomegalovirus infection of breast milk and transmission in infancy. Pediatrics 1983; 72:295-299.

59. Ekanem EE, DuPont HL, Pickering LK, et al: Transmission dynamics of enteric bacteria in day-care centers. Am J Epidemiol 1983; 118:562-572.

60. Ellison RT III, Kohler PF, Curd JG, et al: Prevalence of congenital or acquired complement deficiency in patients wtih sporadic meningococcal disease. $N$ Engl $J$ Med 1983; 308:913-916.

61. Estes SA: Diagnosis and management of scabies. Med Clin North Am 1982; 66:955-963.

62. Ewasechko C: Prevalence of head lice (Pediculus capitis [De Geer]) among children in a rural, central Alberta school. Can $J$ Public Health 1981; $72: 249-252$.

63. Feigin RD, Cherry JD (eds): Textbook of Pediatric Infectious Diseases. Philadelphia, WB Saunders Co, 1981.

64. Foster MT Jr, Sanders E, Ginter M: Epidemiology of sulfonamide-resistant meningococcal infection in a civilian population. Am $J$ Epidemiol 1971; 93:346-353.

65. Fraser DW, Geil CC, Feldman RA: Bacterial meningitis in Bernalillo County, New Mexico: A comparison with three other American populations. Am J Epidemiol 1974; 100:29-34.

66. Friedman HM, Lewis MR, Nemerofsky DM, et al: Acquisition of cytomegalovirus infection among female employees at a pediatric hospital. Pediatr Infect Dis 1984; 3:233-235.

67. Gershon AA: Prevention and treatment of varicella-zoster virus infection. Pediatr Infect Dis 1984; 3:S34-S36.

68. Ginsburg CM: Scabies. Pediatr Infect Dis 1984; 3:133-134. 
69. Ginsburg CM, Lowry W, Reisch JS: Absorption of lindane (gamma benzene hexachloride) in infants and children. $J$ Pediatr 1977; 91:998-1000.

70. Glezen WP, Couch RB: Interpandemic influenza in the Houston area. $N$ Engl J Med 1978; 298:587-592.

71. Glezen WP, Denny FW: Epidemiology of acute lower respiratory disease in children. $N$ Engl J Med 1973; 288:498-505.

72. Gold R, Goldschneider I, Lapow ML, et al: Carriage of Neisseria meningitidis and Neisseria lactamica in infants and children. $J$ Infect Dis 1978; 137:112-121.

73. Goldenring JM, David J, McChesney M: Pediatric screening of Southeast Asian immigrants. Clin Pediatr 1982; 21:613-616.

74. Granoff DM, Basden M: Haemophilus influenzae infections in Fresno County, California: A prospective study of the effects of age, race, and contact with a case on incidence of disease. $J$ Infect Dis 1980; 141:40-46.

75. Granoff DM, Daum RS: Spread of Haemophilus influenzae type b: Recent epidemiologic and therapeutic considerations. $J$ Pediatr 1980; 97:854-860.

76. Granoff DM, Gilsdorf J, Gessert C, et al: Haemophilus influenzae type B disease in a day-care center: Eradication of carrier state by rifampin. $P e$ diatrics $1979 ; 63: 397-401$.

77. Granoff DM, Squires JE: Hemophilus meningitis: New developments in epidemiology, treatment and prophylaxis. Semin Neurol 1982; 2:151-165.

78. Gustafson TL, Lavely GB, Brawner ER Jr, et al: An outbreak of airborne nosocomial varicella. Pediatrics 1982; 70:550-556.

79. Gwaltney JM Jr, Moskalski PB, Hendley JO: Hand-to-hand transmission of rhinovirus colds. Ann Intern Med 1978; 88:463-467.

80. Haddy RI, Gordon RC, Shamiyeh L, et al: Erythromycin resistance in Group A beta-hemolytic streptococci. Pediatr Infect Dis 1982; 1:236-238.

81. Hadler SC, Erben JJ, Francis DP, et al: Risk factors for hepatitis A in daycare centers. J Infect Dis 1982; 145:255-261.

82. Hadler SC, Erben JJ, Matthews D, et al: Effect of immunoglobulin on hepatitis $\mathrm{A}$ in day-care centers. JAMA $1983 ; 249: 48-53$.

83. Hadler SC, Webster HM, Erben JJ, et al: Hepatitis A in day-care centers: A communily-wide ussessment. $N$ Engl $J$ Med 1980; 302:1222-1227.

84. Hall CB, Breese BB: Does penicillin make Johnny's strep throat better? Pediatr Infect Dis 1984; 3:7-9.

85. Hall CB, Douglas RG Jr: Modes of transmission of respiratory syncytial virus. J Pediatr 1981; 99:100-103.

86. Hall CB, Douglas RG Jr, Geiman JM: Possible transmission by fomites of respiratory syncytial virus. J Infect Dis $1980 ; 141: 98-102$.

87. Hall CB, Geiman JM, Biggar R, et al: Respiratory syncytial virus infections within families. $N$ Engl $J$ Med 1976; 294:414-419.

88. Haltalin KC, Nelson JD: Coliform septicemia complicating shigellosis in children. JAMA 1965; 192:441-443.

89. Hanshaw JB, Scheiner AP, Moxley AW, et al: School failure and deafness after "silent" congenital cytomegalovirus infection. N Engl J Med 1976; 295:468-470.

90. Henle G, Henle W, Wendell KK, et al: Isolation of mumps virus from human beings with induced apparent or inapparent infections. J Exp Med 1948; 88:223-232.

91. Hinman AR, Koplan JP: Pertussis and pertussis vaccine: Reanalysis of benefits, risks, and costs. JAMA 1984; 251:3109-3113.

92. Hodes HL: Viral gastroenteritis. Am J Dis Child 1977; 131:729-731.

93. Hoekelman RA, Starfield B, McCormick M, et al: A profile of pediatric practice in the United States. Am J Dis Child 1983; 137:1057-1060.

94. Hsu KHK: Thirty years after isoniazid: Its impact on tuberculosis in children and adolescents. JAMA 1984; 251:1283-1285.

95. Huang E-S, Alford CA, Reynolds DW, et al: Molecular epidemiology of cytomegalovirus infections in women and their infants. $N$ Engl $J$ Med 1980; 303:958-962.

96. Hurwitz S: Scabies in babies. Am J Dis Child 1973; 126:226-228. 
97. Hurwitz S: Update: Scabies in childhood. Pediatr Ann 1982; 11:226-236.

98. Hyams PJ, Steuwe MC, Heitzer V: Herpes zoster causing varicella (chickenpox) in hospital employees: Cost of a casual attitude. Am J Infect Control $1984 ; 12: 2-5$.

99. Iowa State Department of Public Health: Scabies in institutions. J Iowa Med Soc 1981; 71:78-79.

100. Istre G, Conner J, Hopkins R, et al: Case control study of systemic $H$. influenzae (HI) infections: An increased risk from day-care attendance, in Program and Abstracts of the Twenty-Third Interscience Conference on Antimicrobial Agents and Chemotherapy, Las Vegas, October 24-26, 1983. Washington, DC, American Society for Microbiology, 1983, Abst No 787, p 229.

101. Jacobson JA, Filice GA, Holloway JT: Meningococcal disease in day-care centers. Pediatrics 1977; 59:299-300.

102. Jones L, Duke P, Yeager A: Cytomegalovirus (CMV) infections: Infant development vs. day-care centers. Pediatr Res 1984; 18:278A.

103. Kaiser AB, Hennekens CH, Saslaw MS, et al: Seroepidemiology and chemoprophylaxis of disease due to sulfonamide-resistant Neisseria meningitidis in a civilian population. $J$ Infect Dis 1974:130:217-224.

104. Kaplan EL: The group A streptococcal upper respiratory tract carrier state: An enigma. $J$ Pediatr 1980; 97:337-345.

105. Karmali MA, Fleming PC: Campylobacter enteritis in children. J Pediatr 1979; 94:527-533.

106. Kaupas V: Tuberculosis in a family day-care home: Report of an outbreak and recommendations for prevention. JAMA 1974; 228:851-854.

107. Keh B: Answers to some questions frequently asked about pediculosis. Calif Vector Views 1979; 26:51-62.

108. Keswick BH, Pickering LK, DuPont HL, et al: Survival and detection of rotaviruses on environmental surfaces in day-care centers. Appl Environ Microbiol 1983; 46:813-816.

109. Klein JO, Brunell PA, Cherry JD, et al (eds): Report of the Committee on Infectious Diseases, ed 19. Evanston, Illinois, American Academy of Pediatrics, 1982.

110. Klein JO, Remington JS, Marcy SM: Current concepts of infections of the fetus and newborn infant, in Remington JS, Klein JO (eds): Infectious Diseases of the Fetus and Newborn Infant ed 2. Philadelphia, WB Saunders Co, $1983, \mathrm{pp} 1-26$.

111. Lee B, Groth P: Scabies: Transcutaneous poisoning during treatment. Pediatrics $1977 ; 59: 643$.

112. Lemp GF, Woodward WE, Pickering LK, et al: The relationship of staff to the incidence of diarrhea in day-care centers. Am J Epidemiol 1984; 120:750-758.

113. Levine JI, Chapman SS, Guerra V, et al: Studies on the transmission within families of group A hemolytic streptococci. J Lab Clin Med 1966; 67:483-494.

114. Levinsohn EM, Foy HM, Kenny GE, et al: Isolation of cytomegalovirus from a cohort of 100 infants throughout the first year of life. Proc Soc Exp Biol Med 1969; 132:957-962.

115. Lieb S, Gunn RA, Taylor DN: Salmonellosis in a day-care center. $J$ Pediatr $1982 ; 100: 1004-1005$.

116. Linneman CC Jr, Dine MS, Roselle GA, et al: Measles immunity after revaccination: Results in children vaccinated before 10 months of age. Pediatrics 1982; 69:332-335.

117. Lynfield YL, O’Donoghue MN: Pediculosis therapy. $J$ Am Acad Dermatol $1982 ; 6: 949-950$.

118. Martin T, Habbick BF, Nyssen J: Shigellosis with bacteremia: A report of two cases and a review of the literature. Pediatr Infect Dis 1983; 2:21-26.

119. Maunder JW: Human lice: Biology and control. $R$ Soc Health $J$ 1977; 97:29-32.

120. Maynard JE, Bradley DW, Hornbeck CL, et al: Preliminary serologic stud- 
ies of antibody to hepatitis A virus in populations in the United States. $J$ Infect Dis 1976; 134:528-530.

121. McCaustland KA, Bond WW, Bradley DW, et al: Survival of hepatitis A virus in feces after drying and storage for 1 month. $J$ Clin Microbiol 1982; 16:957-958.

122. McIntosh K: Varicella vaccine: Decisions a little nearer. $N$ Engl $J$ Med $1984 ; 310: 1456-1457$.

123. Medical Letter: Malathion for treatment of head lice. Med Lett 1983; 25:3031.

124. Mellanby K: Scabies in 1976. $R$ Soc Health $J 1977 ; 97: 32-40$.

125. Munford RS, Sussaurana de Vasconcelos ZJ, Phillips CJ, et al: Eradication of carriage of Neisseria meningitidis in families: A study in Brazil. $J$ Infect Dis $1974 ; 129: 644-649$.

126. Murphy TV, Breedlove JA, Fritz EH, et al: County-wide surveillance of invasive Haemophilus infections: Risk of associated cases in child care programs (CCPs), in Program and Abstracts of the Twenty-Third Conference on Antimicrobial Agents and Chemotherapy, Las Vegas, October 24-26, 1983. Washington, DC, American Society for Microbiology, 1983, Abst No $788, \mathrm{p} 229$.

127. Murphy TV, McCracken GH Jr, Moore BS, et al: Haemophilus influenzae type b disease after rifampin prophylaxis in a day-care center: Possible reasons for its failure. Pediatr Infect Dis 1983; 2:193-198.

128. Nelson JD: Antibiotic therapy for Salmonella syndromes. Am J Dis Child 1981; 135:1093-1094.

129. Nelson JD: The changing epidemiology of pertussis in young infants: The role of adults as reservoirs of infection. A $m J$ Dis Child 1978; 132:371-373.

130. Nelson JD: The effect of penicillin therapy on the symptoms and signs of streptococcal pharyngitis. Pediatr Infect Dis 1984; 3:10-13.

131. Nelson JD, Dillon HC Jr, Howard JB: $\Lambda$ prolonged nursery epidemic associated with a newly recognized type of group A streptococcus. $J$ Pediatr $1976 ; 89: 792-796$.

132. Nelson JD, Kusmiesz H, Jackson LH, et al: Treatment of Salmonella gastroenteritis with ampicillin, amoxicillin, or placebo. Pediatrics 1980; 65:1125-1130.

133. Nelson JD, Kusmiesz H, Jackson LH, et al: Trimethoprim-sulfamethoxazole therapy for shigellosis. JAMA 1976; 235:1239-1243.

134. Nitzkin JL: Pediculosis capitis. JAMA 1977; 237:530.

135. Norkrans G, Svedhem Å: Epidemiological aspects of Campylobacter jejuni enteritis. $J$ Hyg (Lond) 1982; 89:163-170.

136. Orkin M, Epstein E Sr, Maibach HI: Treatment of today's scabies and pediculosis. JAMA 1976; 236:1136-1139.

137. Orkin M, Maibach HI: This scabies pandemic. $N$ Engl J Med 1978; 298:496-498.

138. Pai CH, Gillis F, Tuomanen E, et al: Erythromycin in treatment of Campylobacter enteritis in children. Am J Dis Child 1983; 137:286-288.

139. Pai CH, Sorger S, Lackman L, et al: Campylobacter gastroenteritis in children. J Pediatr 1979; 94:589-591.

140. Paisley JW, Mirrett S, Lauer BA, et al: Dark-field microscopy of human feces for presumptive diagnosis of Campylobacter fetus, subspecies jejuni enteritis. $J$ Clin Microbiol 1982; 15:61-63.

141. Park CH, Hixon DL, Polhemus AS, et al: A rapid diagnosis of Campylobacter enteritis by direct smear examination. Am J Clin Pathol 1983; 80:388390.

142. Pass RF, August AM, Dworsky M, et al: Cytomegalovirus infection in a day-care center. $N$ Engl $J$ Med 1982; 307:477-479.

143. Pass RF, Hutto SC, Reynolds DW, et al: Increased frequency of cytomegalovirus infection in children in group day-care. Pediatrics $1984 ; 74: 121-$ 126.

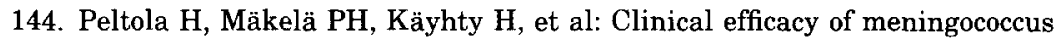


Group A capsular polysaccharide vaccine in children three months to five years of age. $N$ Engl $J$ Med 1977; 297:686-691.

145. Pickering LK, Evans DG, DuPont HL, et al: Diarrhea caused by Shigella, rotavirus, and Giardia in day-care centers: Prospective study. $J$ Pediatr 1981; 99:51-56.

146. Pickering LK, Woodward WE: Diarrhea in day-care centers. Pediatr Infect Dis $1982 ; 1: 47-52$.

147. Pickering LK, Woodward WE, DuPont HL, et al: Occurrence of Giardia lamblia in children in day-care centers. $J$ Pediatr 1984; 104:522-526.

148. Pollock TM, Miller E, Lobb J: Severity of whooping cough in England before and after the decline in pertussis immunization. Arch Dis Child 1984; 59:162-165.

149. Poorbaugh JH: Head lice infestation-update on control measures. Calif Morb 1983; 3:1.

150. Powell KE, Brown ED, Farer LS: Tuberculosis among Indochinese refugees in the United States. JAMA 1983; 249:1455-1460.

151. Powell KE, Meador MP, Farer LS: Recent trends in tuberculosis in children. JAMA 1984; 251:1289-1292.

152. Preblud SR: Age-specific risks of varicella complications. Pediatrics 1981; 68:14-17.

153. Ramras $D$, et al: Interstate importation of measles following transmission in an airport-California, Washington, 1982. MMWR 1983; 32:210-215.

154. Rendtorff RC: The experimental transmission of human intestinal protozoan parasites. II. Giardia lamblia cysts given in capsules. Am J Hyg 1954; 59:209-220.

155. Rodriguez WJ, Kim HW, Brandt CD, et al: Common exposure outbreak of gastroenteritis due to type 2 rotavirus with high secondary attack rate within families. $J$ Infect Dis 1979; 140:353-357.

156. Rosenberg ML, Weissman JB, Gangarosa EJ, et al: Shigellosis in the United States: Ten-year review of nationwide surveillance, 1964-1973. Am $J$ Epidemiol 1976; 104:543-551.

157. Rosenstein BJ: Salmonellosis in infants and children: Epidemiologic and therapeutic considerations. J Pediatr 1967; 70:1-7.

158. Rubin RH, Weinstein L: Salmonellosis: Microbiologic, Pathologic and Clinical Features. New York, Stratton Intercontinental Medical Book Corp, 1977.

159. San Joaquin VH, Marks MI: New agents in diarrhea. Pediatr Infect Dis $1982 ; 1: 53-65$.

160. Schaad UB: Reactive arthritis associated with campylobacter enteritis. Pediatr Infect Dis 1982; 1:328-332.

161. Schroeder SA, Aserkoff B, Brachman PS: Epidemic salmonellosis in hospitals and institutions: A five-year review. $N$ Engl J Med 1968; 279:674-678.

162. Sealy DP, Schuman SH: Endemic giardiasis and day care. Pediatrics 1983; 72:154-158.

163. Shaw PK, Juranek DD: Recent trends in scabies in the United States. $J$ Infect Dis 1976; 134:414-416.

164. Starfield B, Katz H, Gabriel A, et al: Morbidity in childhood-A longitudinal view. $N$ Engl J Med 1984; 310:824-829.

165. Steinhoff MC: Rotavirus: The first five years. J Pediatr 1980; 96:611-622.

166. Storch G, McFarland LM, Kelso K, et al: Viral hepatitis associated with day-care centers. JAMA 1979; 242:1514-1518.

167. Strangert $\mathrm{K}$, Carlström G, Jeansson $\mathrm{S}$, et al: Infections in preschool children in group day care. Acta Paediatr Scand 1976; 65:455-463.

168. Ström J: A study of infections and illnesses in a day nursery based on inclusion-bearing cells in the urine and infectious agent in faeces, urine and nasal secretion. Scand $J$ Infect Dis 1979; 11:265-269.

169. Sullivan P, Woodward WE, Pickering LK, et al: Longitudinal study of occurrence of diarrheal disease in day care centers. Am J Public Health 1984; 74:987--991. 
170. Swansea Research Unit of the Royal College of General Practitioners: Effect of a low pertussis uptake on a large community. $\mathrm{Br} \mathrm{Med} J$ 1981; 282:23-26.

171. Tacket CO, Cohen ML: Shigellosis in day care centers: Use of plasmid analysis to assess control measures. Pediatr Infect Dis 1983; 2:127-130.

172. Taplin D, Arrue C, Walker JG, et al: Eradication of scabies with a single treatment schedule. $J$ Am Acad Dermatol 1983; 9:546-550.

173. Taplin D, Castillero PM, Spiegel J, et al: Malathion for treatment of Pediculus humanus var capitis infestation. JAMA 1982; 247:3103-3105.

174. Tejani A, Dobias B, Nangia BS, et al: Intrafamily spread of Haemophilus type b infections. Am J Dis Child 131:778-781, 1977.

175. Toews WH, Bass JW: Skin manifestations of meningococcal infection: An immediate indicator of prognosis. Am J Dis Child 1974; 127:173-176.

176. Torphy DE, Bond WW: Campylobacter fetus infections in children. Pediatrics $1979 ; 64: 898-903$.

177. Use of immune globulin for control of day care center hepatitis A outbreaks. (Adapted from: Centers for Disease Control Hepatitis Surveillance Report No. 47, December, 1981.) Calif Morb 1982; 22:1.

178. Walder M: Epidemiology of Campylobacter enteritis. Scand J Infect Dis $1982 ; 14: 27-33$.

179. [Adapted from] Walton C.: Contra Costa County Health Department Report: Why report a case of shigellosis? (an outbreak in a day care center). Calif Morb 1979; 28:1.

180. Ward JI, Fraser DW, Baraff LJ, et al: Haemophilus influenzae meningitis: A national study of secondary spread in household contacts. $N$ Engl J Med $1979 ; 301: 122-126$.

181. Ward JI, Gorman G, Phillips C, et al: Hemophilus influenzae type b disease in a day-care center: Report of an outbreak. $J$ Pediatr 1978; 92:713-717.

182. Weissman JB, Gangarosa EJ, Schmerler A, et al: Shigellosis in day-care centres. Lancet $1975 ; 1: 88-90$.

183. Weissman JB, Schmerler A, Weiler $P$, et al: The role of preschool children and day-care centers in the spread of shigellosis in urban communities. $J$ Pediatr 1974; 84:797-802.

184. Weller TH: Varicella and herpes zoster: Changing concepts of the natural history, control, and importance of a not-so-benign virus. $N \mathrm{Engl} J \mathrm{Med}$ $1983 ; 309: 1362-1368$.

185. Weller TH: Varicella and herpes zoster: Changing concepts of the natural history, control, and importance of a not-so-benign virus. II. $N$ Engl J Med $1983 ; 309: 1434-1440$.

186. Wentworth BB, Alexander ER: Seroepidemiology of infections due to members of the herpesvirus group. Am $J$ Epidemiol 1971; 94:496-507.

187. Wilkins J, Wehrle PF: Additional evidence against measles vaccine administration to infants less than 12 months of age: Altered immune response following active/passive immunization. J Pediatr 1979; 94:865-869.

188. Williams SV, Huff JC, Bryan JA: Hepatitis A and facilities for preschool children. J Infect Dis 1975; 131:491-495.

189. Wilson R, Feldman RA, Davis J, et al: Salmonellosis in infants: The importance of intrafamilial transmission. Pediatrics 1982; 69:436-438.

190. Wolfe MS: Current concepts in parasitology: Giardiasis. $N$ Engl $J$ Med $1978 ; 298: 319-321$.

191. Wolfe MS: Giardiasis. JAMA 1975; 233:1362-1365.

192. Yeager AS: Longitudinal, serological study of cytomegalovirus infections in nurses and in personnel without patient contact. $J$ Clin Microbiol 1975; 2:448-452.

193. Yeager AS: Transmission of cytomegalovirus to mothers by infected infants: Another reason to prevent transfusion-acquired infections. Pediatr Infect Dis 1983; 2:295-297.

194. Yeager AS, Davis JH, Ross LA, et al: Measles immunization: Successes and failures. JAMA 1977; 237:347-351. 